Portland State University

PDXScholar

\title{
Effects of Steel Type and Sandblasting Pretreatment on the Solid-liquid Compound Casting Characteristics of Zinc-coated Steel/aluminum Bimetals
}

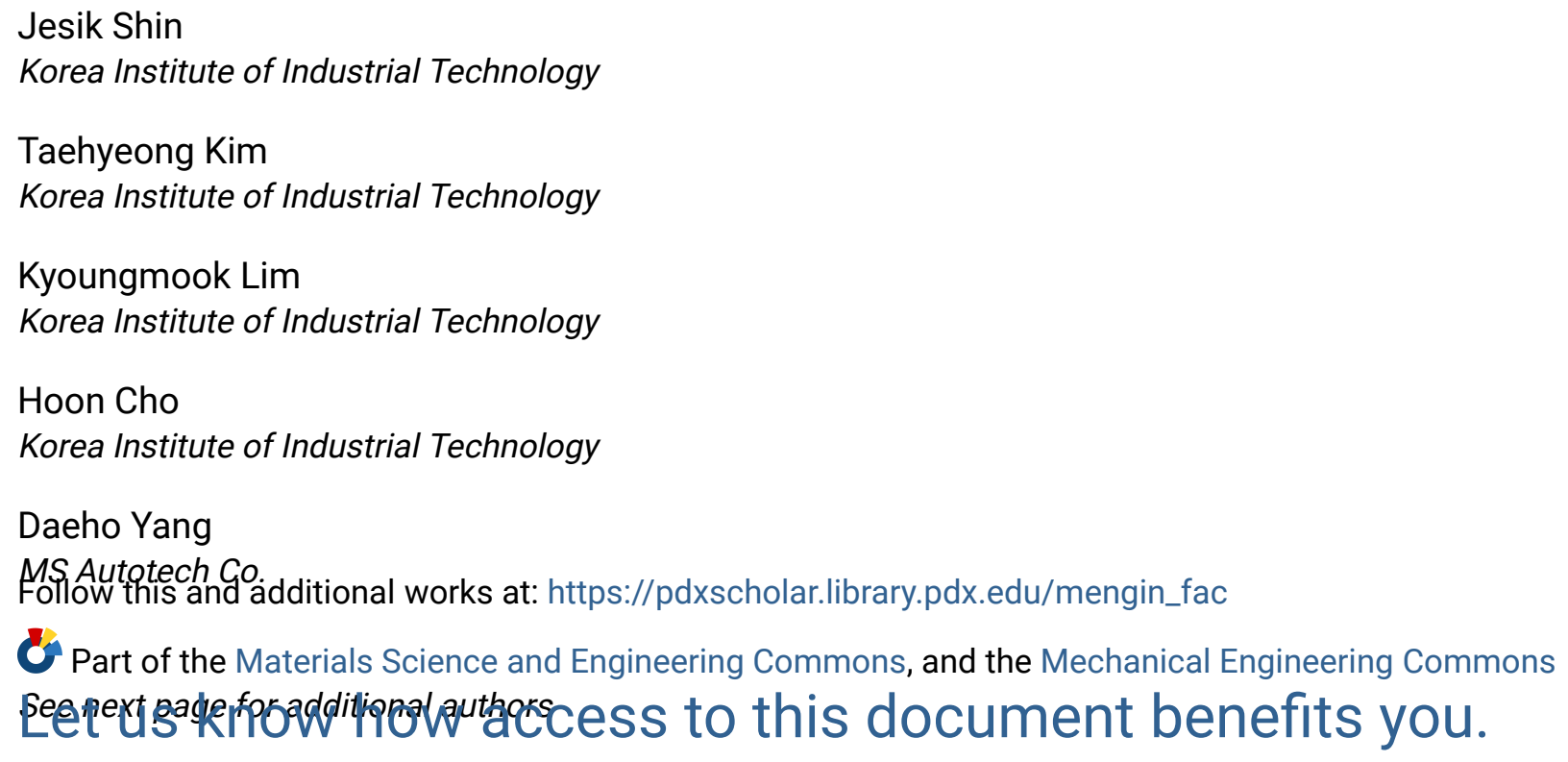

\section{Citation Details}

Shin, J., Kim, T., Lim, K., Cho, H., Yang, D., Jeong, C., \& Yi, S. (2019). Effects of steel type and sandblasting pretreatment on the solid-liquid compound casting characteristics of zinc-coated steel/aluminum bimetals. Journal of Alloys \& Compounds, 778, 170-185. https://doi.org/10.1016/j.jallcom.2018.11.134

This Post-Print is brought to you for free and open access. It has been accepted for inclusion in Mechanical and Materials Engineering Faculty Publications and Presentations by an authorized administrator of PDXScholar. Please contact us if we can make this document more accessible: pdxscholar@pdx.edu. 


\section{Authors}

Jesik Shin, Taehyeong Kim, Kyoungmook Lim, Hoon Cho, Daeho Yang, Changyeol Jeong, and Sung Yi 


\section{Accepted Manuscript}

Effects of steel type and sandblasting pretreatment on the solid-liquid compound casting characteristics of zinc-coated steel/aluminum bimetals

Jesik Shin, Taehyeong Kim, Kyoungmook Lim, Hoon Cho, Daeho Yang, Changyeol Jeong, Sung Yi

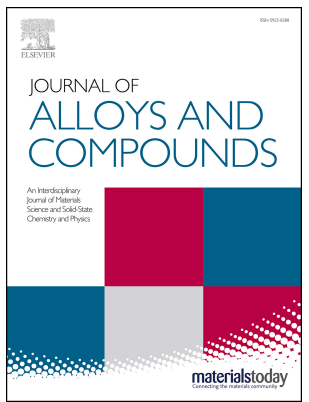

PII:

S0925-8388(18)34257-9

DOI: https://doi.org/10.1016/j.jallcom.2018.11.134

Reference: JALCOM 48360

To appear in: Journal of Alloys and Compounds

Received Date: 24 July 2018

Revised Date: 9 November 2018

Accepted Date: 11 November 2018

Please cite this article as: J. Shin, T. Kim, K. Lim, H. Cho, D. Yang, C. Jeong, S. Yi, Effects of steel type and sandblasting pretreatment on the solid-liquid compound casting characteristics of zinccoated steel/aluminum bimetals, Journal of Alloys and Compounds (2018), doi: https://doi.org/10.1016/ j.jallcom.2018.11.134.

This is a PDF file of an unedited manuscript that has been accepted for publication. As a service to our customers we are providing this early version of the manuscript. The manuscript will undergo copyediting, typesetting, and review of the resulting proof before it is published in its final form. Please note that during the production process errors may be discovered which could affect the content, and all legal disclaimers that apply to the journal pertain. 
Effects of steel type and sandblasting pretreatment on the solid-liquid compound casting characteristics of zinc-coated steel/aluminum bimetals

Jesik Shin ${ }^{\mathrm{add}, *}$, Taehyeong Kim ${ }^{\mathrm{a}}$, Kyoungmook Lim ${ }^{\mathrm{a}}$, Hoon Cho ${ }^{\mathrm{a}}$, Daeho Yang ${ }^{\mathrm{b}}$, Changyeol Jeong ${ }^{\mathrm{c}}$, Sung $\mathrm{Yi}^{\mathrm{d}, *}$

${ }^{\mathrm{a}, \mathrm{d}}$ Korea Institute of Industrial Technology (KITECH), Gaetbeol-ro 156, Yeonsu-gu, Incheon 21999, Republic of Korea

${ }^{\mathrm{b}}$ MS Autotech Co., Ltd., Poseok-ro 16-9, Naenam-myeon, Gyeongju-si, Gyeongsangbuk-do 38198, Republic of Korea

${ }^{\mathrm{c}}$ Dept. of Nuclear \& Energy System Engineering, Dongguk University, Dongdae-ro 123, Gyeongju-si, Gyeongsangbuk-do 38066, Republic of Korea

${ }^{\mathrm{d}}$ Dept. of Mechanical \& Materials Engineering, Portland State University, 1930 SW 4th Ave., Portland, OR 97201, USA

\begin{abstract}
Effects of zinc-coated steel type and steel surface sandblasting pretreatment in the solidliquid compound casting of layered type steel/aluminum bimetals were investigated. The $\mathrm{Zn}$ coating behavior and its effects on interfacial microstructure evolution and fracture mechanism were also discussed. The aluminum fluidity in thin plate type flow channels formed by the steel insert and the mold wall primarily depended on the insert surface roughness and secondarily on the wettability. As-galvanized (GI) steel/aluminum bimetal joints showed the bonding strength of $20 \mathrm{MPa}$ and more, while galvannealed (GA) steels showed poor bonding. The interfacial bonding zone consisted of most $\mathrm{Al}_{13} \mathrm{Fe}_{4}, \mathrm{Al}_{8} \mathrm{Fe}_{2} \mathrm{Si}, \mathrm{Al}_{4.5} \mathrm{FeSi}$ intermetallic phases, as well as some $\mathrm{Si}$ phases. $\mathrm{A}$
\end{abstract}


low temperature and short time of the bonding reaction coupled with a high silicon content of the aluminum alloy suppressed the formation of $\mathrm{Al}_{5} \mathrm{Fe}_{2}$ phase. Oxide scales on the GA steel surface prevented the molten $\mathrm{Zn}$ coating from mixing with the aluminum melt. The $\mathrm{Zn}$ coating of GI steels was rapidly disappeared from the steel surface by the chemical affinity and surface energy-driven fluid flow as well as the diffusion, resulting in the formation of $\mathrm{Zn}$-free intermetallic phases. The $\mathrm{Zn}$ coating of GI steels played a role in retarding the onset of bonding reaction. A long time sandblasting caused an excessive growth of intermetallic layers and the formation of Kirkendall voids on the steel side, resulting in the shift of main fracture sites and a slight decrease of the bonding strength.

Key words: zinc-coated steel; layered type bimetal; compound casting; $\mathrm{Zn}$ coating behavior; interfacial microstructure evolution; fracture mechanism

\section{INTRODUCTION}

More increasingly stringent regulations for vehicle safety such as small overlap and new oblique crash testing protocols have caused a continuous increase of vehicle weight. It is necessary to reduce the increase of vehicle weight in the view of fuel economy [14]. Under these circumstances, combining the lightweight properties of aluminum with the strength and formability of steel is receiving a world-wide attention as a technical solution to resolve the conflict between a higher demand for safety and a fuel economy improvement [5].

There are many methods to join aluminum and steel such as welding, roll bonding, diffusion bonding, and compound casting [6]. However, the manufacture of zinc-coated steel/aluminum hybrid components by the compound casting has been reported in few 
literatures, and still remains as a relatively unexplored area $[7,8]$. The requirements for improving durability in vehicle structure have led to the wide use of zinc-coated steel sheets with low cost and superior sacrificial anode effect as a corrosion resistant material $[4,9]$. However, most studies to date mainly have focused on the joining of aluminum alloy and general carbon steels. Relatively fewer research groups have studied the joining of aluminum alloys and zinc-coated steels [8]. As a result, the understanding on the role of $\mathrm{Zn}$ coating in joining of aluminum alloys to steels is still ambiguous [10].

The compound casting is a process of joining two metals via direct casting in which one component is in the solid state, as an insert, and the other as pouring metal. This method is a very attractive manufacturing process for automotive components with complex shapes due to the benefits of cost-effectiveness, high production rate, and net shaping capability [11]. Despite these many benefits, it still remains difficult to get the aluminum to firmly join to steel inserts because of oxide scales on steel surface and large differences in the thermal-physical properties between those two metals, such as melting point and thermal expansion coefficient, which lead to poor wetting and metallurgical bonding [12,13]. Especially, in a form in which aluminum and steel are layered in parallel, rather than a form in which steel is embedded in aluminum, their joining becomes much more difficult because the shrink fitting effect is not available. The chemical reaction between aluminum and steel is known to be difficultly triggered when pure aluminum melt is directly poured to iron and steel inserts without special pretreatments [14-16].

In order to improve the ability of compound casting of aluminum alloys and steels, diverse steel surface treatment methods have been tried. An interlayer coated on the 
substrate surface (such as $\mathrm{Al}-$ Fin process) is the most common approach to increase the wettability of steel substrates. The Al-Fin process is a method to coat aluminum alloys on the surface of ferrous metals by hot-dipping. And also there are many reports that zinc and zinc alloys can also serve as a good interlayer former to achieve a sound joint of dissimilar metals [15]. The zinc coating can not only protect the base ferrous metals from the oxidation in air, but also improve the wettability between the base ferrous metals and the molten aluminum alloys. However, most studies have been reported to join the aluminum alloys to the zinc-coated steels by welding processes, but very little works have been done on the compound casting [14]. This research tendency seems to be attributed to the fact that the joining reaction in compound casting processes must occur over a larger area at a lower temperature and/or with lower density energy unlike welding, and as a result obviously the metallurgical bonding becomes more difficult. For the purpose of improving the ability of compound casting of aluminum and steel, the effects of chemical and mechanical pretreatments of steel surface on mechanical grip and oxides elimination have been also reported [17,18]. Kim et al. [17] formed several hundred micrometer-sized pits on $\mathrm{Fe}-17 \mathrm{Cr}$ steel surface by electrochemical etching prior to compound casting. However, such chemical surface treatments need many process steps and also require a careful attention to prevent further etching, which deteriorates the wettability with aluminum melt. Bouayad et al. [18] reported that the sandblasting pretreatment on the insert surface prior to compound casting had a notable influence on eliminating oxides and improving mechanical grip in aluminum and SG (Spheroidal Graphite) iron bimetal system. Above all, the sandblasting is probably the most easily adopted method in conventional foundries due to its high productivity and 
economic efficiency, because it is a very simple and low-cost process for mechanical surface pretreatment. On the other hand, Cheng et al. [19] reported a contrary effect of the interfacial roughness on bimetallic bonding, i.e. an irregular shape of intermetallic phase/steel substrate acts as a stress concentrator, causing cracks more easily than a flat interface when external loads are applied. Although various investigations have been carried out to improve the ability of compound casting, how to achieve an excellent bonding of layered aluminum and steel sheets by casting is still quite challenging subject $[14,15]$.

In this study, the effects of steel type and sandblasting surface pretreatment level on the compound casting characteristics such as casting properties and structural integrity of zinc-coated steel/aluminum bimetals are investigated to develop an industrially applicable joining process for layered type aluminum/steel bimetallic parts. Two kinds of zinc-coated steels, as-galvanized (GI) and galvannealed (GA) steels, and A356 aluminum alloy are used as insert and casting materials, respectively. Casting properties such as mold filling-ability and fluidity, which affect near net shaping of complex shaped components, are evaluated in thin plate type flow channels, which are formed by the zinc-coated steel insert and the steel mold wall, and tried to be interpreted in connection with the aluminum melt wettability and the steel surface roughness. To evaluate the structural integrity of the layered type bimetal, firstly, the interfacial bonding strength is examined by the tensile shear test. Secondly, the fractographic analysis on fractured surfaces and the metallurgical characterization on bonding interfaces are performed. This study focuses on studying the $\mathrm{Zn}$ coating behavior during compound casting process by using a quenching technique and discusses its effects on the interfacial microstructure evolution and the fracture mechanism. 


\section{EXPERIMENTAL}

\subsection{Materials}

In the present study, two kinds of zinc-coated steels, i.e. as-galvanized $980 \mathrm{MPa}$ dual phase steel (DP980-GI) and galvannealed 590 MPa dual phase steel (DP590-GA), were used as an insert material for the compound casting. The thickness of the steels was 1.4 mm. As a casting material, A356 aluminum alloy which is the most common commercial cast aluminum alloy was used. The chemical compositions of those steels and aluminum alloy are listed in Tables 1 and 2.

\subsection{Sandblasting pretreatment of inserts}

Prior to the compound casting process, the zinc-coated steels were surface-treated by sandblasting with 60-mesh brown aluminum oxide particles. The sandblasting machine MPTB $^{-1}$ with blasting pressure of 8 bars and blasting nozzle of $8 \mathrm{~mm}$ diameter was used. Three sets of steel specimens having different residual $\mathrm{Zn}$ coating layer thickness and surface roughness were prepared by varying the sandblasting time as followings: as-received (AR), sandblasted for $5 \mathrm{sec}$ (SB5), and sandblasted for $30 \mathrm{sec}$ (SB30). The blasting angle was $90^{\circ}$ and the working distance from the nozzle to the sample surface was about $20 \mathrm{~cm}$. The surface roughness average $(R a)$ of the sandblasted steels was measured using a 3D laser scanning microscope (INSIS-AF).

\subsection{Evaluation of castability and interfacial bonding strength}

The fluidity of A356 aluminum alloy melt on the zinc-coated steels was carried out 
using a BN-coated steel mold with multi flow channels (Fig. 1a). The flow channels were $100 \mathrm{~mm}$ long and open to the air at the end, and their thicknesses were 1, 2, 3, and $4 \mathrm{~mm}$. The zinc-coated steel sheets were cut into rectangular inserts of $130 \mathrm{~mm}$ long by $56 \mathrm{~mm}$ wide, and inserted into the mold cavity machined to match them. The thin plate type flow channels were formed by the zinc-coated steel inserts on one side and the steel mold wall on the other side. In order to prevent the oxidation of the aluminum melt during tests and evaluate the fluidity as functions of zinc-coated steel type and sandblasting condition only, the mold was mounted on a low pressure casting machine under an inert-gas atmosphere. The steel inserts were cut into rectangular inserts of 130 $\mathrm{mm}$ length by $56 \mathrm{~mm}$ width, and sandblasted as described in section 2.1 , and then inserted into the mold preheated up to $190^{\circ} \mathrm{C}$ using embedded heating cartridges, and hold for $10 \mathrm{~min}$ prior to melt pouring. The superheat temperature of the aluminum alloy melt and the pressure for melt pouring were $100^{\circ} \mathrm{C}$ and $15 \mathrm{kPa}$, respectively. Fig. $1 \mathrm{~b}$ shows the fluidity test casting after solidification. The measurements were performed 810 times to confirm the reproducibility. In order to interpret the fluidity in connection with the wettability between the aluminum alloy melt and the steels substrates, the sessile drop test was performed using the A356 alloy samples of cylinder shape with 15 $\mathrm{mm}$ diameter and $10 \mathrm{~mm}$ thickness. The sessile drop tests were carried out in a tube furnace under an inert-gas atmosphere with a constant superheat condition of $100^{\circ} \mathrm{C}$.

To evaluate interfacial bonding strength, the cast-bonded ingots were prepared using a permanent mold casting with bottom gating system, of which the schematic illustration is shown in Fig. 2a. The zinc-coated steel sheets were cut into rectangular inserts of $176 \mathrm{~mm}$ length by $60 \mathrm{~mm}$ width, and sandblasted as described in section 2.1, and then inserted into the metal mold cavity machined to match them. Fig. $2 \mathrm{~b}$ shows the 
cast-bonded ingot after solidification. The interfacial bonding strength was measured by a tensile shear method. As shown in Fig. 3, the dimensions of the tensile shear specimens having two notches, which are machined in the $\mathrm{Al}$ and $\mathrm{Fe}$ layers, so that the bonding interface can be completely exposed. The tensile shear tests were carried out at room temperature at a cross-head speed of $1 \mathrm{~mm} / \mathrm{min}$ using a universal testing machine (Shimadzu AG-X plus 20kN).

\subsection{Microstructural analysis}

Microstructural examination on the steel- and aluminum-side shear fracture surfaces of the joints was carried out by combined analysis of scanning electron microscopy (SEM) and X-ray diffraction (XRD). The examinations on the fracture mode and the elemental distributions on the fracture surface were carried out using a field emission scanning electron microscope (FESEM, FEI Quanta 200F) equipped with an energydispersive X-ray spectroscopy (EDS) probe. The secondary electron (SE) and backscattered electron (BSE) imaging were used to observe the morphologies of the fracture surfaces and to display the phases with heavy metals on the fracture surfaces. To investigate the structural information of the phases present in the fracture surfaces, the XRD pattern analyses were performed using a PANalytical X'Pert Pro MPD X-ray diffractometer with monochromatic $\mathrm{Cu}$ Ka radiation.

In order to further investigate the crack formation behavior and identify the microstructural phases and the elemental distributions across the bonding reaction layers, more detailed observations and compositional examinations on the polished cross-sections of the as-cast-bonded specimens were conducted using SEM (BSE) imaging and EDS spot and line scanning analyses. 
In order to study the behavior of Zn coating during compound casting process and its effects on microstructural evolution at the interface, the rapidly quenched microstructure was investigated. The quenched samples were obtained using a small steel cup with dimensions of $50 \mathrm{~mm}$ external diameter, $20 \mathrm{~mm}$ height, and $1 \mathrm{~mm}$ wall thickness. After pouring the molten aluminum into the steel cup on which bottom the GI steel was placed, the steel cup was immediately water quenched by dropping into a cooling bath.

\section{RESULTS}

\subsection{Castability and interfacial bonding strength}

Fig. 4 shows cross-sectional SEM micrographs of the GI and GA steels after the sandblasting pretreatments, which were carried out before compound casting. The thickness of residual $\mathrm{Zn}$ coating layer decreases and the surface roughness increases with increasing sandblasting time. However, parts of the $\mathrm{Zn}$ coating still remain partially after the sandblasting pretreatments: it is observed even in the SB30 specimens. Among the GI and GA steels, the Zn coating of GA steels was relatively well removed.

For the actual production of complex structural casting components, aluminum alloys require a high degree of fluidity and castability [20]. To assess the casting properties in the solid-liquid compound casting process of layered steel/aluminum bimetallic parts, the filling ability and fluidity of A356 alloy were evaluated in the thin plate type flow channels formed by the steel inserts and the mold wall. Fig. 5 shows the average flow lengths in the $2 \mathrm{~mm}$ thick flow channel as functions of the zinc-coated steel type and the sandblasting level. The flow channels larger than $2 \mathrm{~mm}$ in thickness were completely filled for both GI and GA steels regardless of the sandblasting level. In the case of the 1 
mm thick flow channel, the aluminum melt hardly reached the steel inserts. In the case of $2 \mathrm{~mm}$ thick flow channel, it is the most noticeable that the flow lengths are remarkably shorter in the sandblasted samples than the non-sandblasted samples for both GI and GA steels. There are little differences between SB5 samples and SB30 samples. Among GI and GA steels, the GA steels show a little higher fluidity.

To evaluate the structural integrity of layered type zinc-coated steel/aluminum bimetals, the tensile shear tests were carried out, with results presented in Figs. 6 and 7. The typical load-displacement curve for cast-bonded GI steel/aluminum specimens is shown in Fig. 6. During the tensile shear tests, brittle fractures occurred in all specimens with no yielding behavior. Negative peaks observed on the load-displacement curve imply the occurrence of local cracks due to interfacial defects. Fig. 7 shows the interfacial bonding strength measured by the tensile shear tests as functions of the zinccoated steel type and the sandblasting level. GI specimens showed good bonding characteristics, while GA steels showed very poor bonding characteristic. The bonding strengths of GI steels are higher than $20 \mathrm{MPa}$, and AR-GI specimen shows the highest value. Meanwhile, in the case of GA steels, only SB30-GA specimens show a meaningful level of interfacial bonding strength, and the AR- and SB5-GA specimens were broken during machining the shear tensile shear specimens or at a very initial testing stage.

\subsection{Surface characterization of the steel inserts}

In order to interpret the effects of steel type and steel surface sandblasting pretreatment on the thin wall fluidity, the wetting characteristics of the GI and GA steels 
with the A356 alloy melt was evaluated by the sessile drop test. A poor wettability between molten metals and mold walls causes a bigger back pressure in a thinner cavity casting condition, leading to a poor mold filling and low fluidity [21,22]. Fig. 8 shows the photographs representing the variation of wettability according to sandblasting level and steel type. As the sandblasting time increases, i.e. the thickness of residual $\mathrm{Zn}$ coating layer decreases, the wetting length decreases in both GI and GA steels. But it is the most noticeable that GI steels show much better wettability than GA steels. Even SB5-GI specimens show better wettability than AR-GA specimens. GA steels show very poor wettability regardless of the sandblasting level. Given that the $\mathrm{Zn}$ coating is generally known to improve the wettability of steel with molten aluminum, it is interesting to note that even non-sandblasted GA steels show very poor wetting. The oxide scale on the $\mathrm{Zn}$ coating of the GA steels seems to deteriorate their wettability to the molten aluminum alloy. In reactive wetting system such as aluminum/steel or aluminum/zinc-coated steel, in which the moving of the triple line is controlled by intermetallic formation reactions at the solid/liquid interface, the spreading of a molten metal on the solid metal substrate is very sensitive to oxide scales [23,24]. Based on the wettability testing results, it can be concluded that wetting property was not the main factor to determine the thin wall fluidity.

The thin wall fluidity seemed to be mainly dependent on the surface roughness in this experimental condition, showing an inverse relationship with the surface roughness. The roughness average, $R a$, measured as functions of the steel type and the sandblasting level are summarized in Fig. 9. For the both GI and GA steels, the $R a$ increases sharply due to the sandblasting. The roughness shows the maximum value at SB5 specimens and rather decreases a little bit at SB30 specimens. This seems to be the main factor 
why the maximum thin wall fluidities were observed at the non-sandblasted specimens. And under the same sandblasting conditions, GI specimens show much higher roughness values than GA specimens. It seems to be attributed to the intermetallic compounds interlayer between the steel matrix and the $\mathrm{Zn}$ coating of GA steels, which will be shown later in the chapter 3.3. Such a rougher surface condition of GI steels is probably the main reason why GI specimens showed relatively lower thin wall fluidities in comparison to GA specimens. On the other hand, even though the $R a$ roughness of SB5-GI specimens was pretty higher than that of SB30-GI specimens, the reason why SB5-GI specimens showed a little higher thin wall fluidity than SB30-GI specimens seems to be due to its much better wettability. It can be concluded that the thin wall fluidity was mainly dependent on the surface roughness and slightly dependent on the wettability.

\subsection{Fractographic analysis}

In order to understand the failure mechanism, the fracture surfaces of the joints were studied by combined analysis of OM, SEM, EDS and XRD. Fig. 10 and Table 3 show the SEM (BSE) and EDS investigation results on the fractured surfaces of AR-GA specimens. In the steel side surface, it was the most noticeable that a high oxygen was detected and needle- or plate-like particles were observed over the whole area. These particles seem to be $\mathrm{Al}_{x} \mathrm{Fe}_{y}$ or $(\mathrm{Al}, \mathrm{Zn})_{x} \mathrm{Fe}_{y}$ intermetallic phases, which formed between steel matrix and Zn coating layers during the galvanizing process [25]. That is probably the reason why high amount of aluminum was observed on the steel side surface even though the interfacial bonding reaction did not occur. In general, small amount of 
aluminum, typically about 5 wt.\%, is added into a molten $\mathrm{Zn}$ bath, resulting in the formation of the intermetallic phase layer which acts as a diffusion barrier [25]. High oxygen content on the steel side surface seems to be attributed to thermal oxidations occurred on the $\mathrm{Zn}$ coating surface and the steel/Zn coating interface during galvaannealing process. In the SEM/BSE image of the steel side surface (see Fig. 10a), the bright and dark regions are residual $\mathrm{Zn}$ coating materials and the aluminum alloy stuck to the steel surface, respectively. In the SEM/BSE micrographs of the aluminum side surface (see Fig. 10b), the variation of brightness from location to location are attributed to a non-uniform distribution of residual $\mathrm{Zn}$ coating materials. It is interesting to note that unlike GI steels, the Zn coating layer mostly did not dissolve into the aluminum alloy melt and re-solidified at the steel/aluminum interface. It is likely that although the $\mathrm{Zn}$ coating layer melted when the molten aluminum alloy with much higher melting point than the zinc was poured, thick and stable oxide scales on the Zn coating surface hindered the mixing with the molten aluminum alloy. This is probably the reason why GA steels showed a poor wettability even in un-sandblasted state in Fig. 8. Elemental Fe was not detected at all on the aluminum side surface, which reveals that the metallurgical bonding reaction did not occur. At some areas of the aluminum side surface, Si contents more than four times higher than the Si composition of the A356 alloy were detected (see EDS analysis result for point 4 marked in Fig. 10a). This was due to the Si phases crystallized in a Zn-rich solution containing very small amount of $\mathrm{Al}$ and $\mathrm{Si}$ atoms, as will be explained later in the chapter 3.5. This is another evidence that the molten $\mathrm{Zn}$ coating did not mix well with the molten aluminum alloy. The important role of $\mathrm{Zn}$ coating during steel/aluminum bonding processes is to remove oxide scales on the steel surface and to improve the wettability [13]. However, the 
SEM/EDS analysis results of Fig. 10 and Table 3 suggested that, in the case of the GA steel, oxide scales on the $\mathrm{Zn}$ coating surface impeded the dissolution of $\mathrm{Zn}$ coating into the molten aluminum alloy and subsequently obstructed the direct contact between the molten aluminum alloy and the steel substrate, thereby preventing the metallurgical bonding reaction of steel and the aluminum alloy. AR- and SB5-GA specimens were de-bonded during machining tensile shear specimens or at a very initial tensile shear testing stage, which was because their interfacial bonding was not by a metallurgical reaction but by an adhesive effect caused by the re-solidification of the $\mathrm{Zn}$ coating layer. SB30-GA steels were able to be cast-bonded by the metallurgical reaction, but the bonding strength was not as high as GI specimens, presumably because the oxide scales were not completely removed at the steel/ Zn coating interface.

Fig. 11 shows representative photographs of fractured surfaces from the tensile shear test for the GI steel/aluminum alloy joints. In the AR-GI specimen (Fig. 11a), smooth and lustrous surfaces were observed on both the steel- and aluminum-side surfaces, which indicates that the fracture surfaces consisted of lustrous facets due to intermetallic compounds and thus no oxidation occurred [26,27]. In the sandblasted specimens, rough and less lustrous surfaces were observed on both the steel- and aluminum-side surfaces, as shown in Fig. 11b. Rough fracture surfaces might be considered that the crack propagation was deflected due to the effect of surface roughness caused by sandblasting pretreatment. It was noticed that the roughness of fracture surfaces was much larger than that of as-sandblasted state. This implies that the fracture occurred not just along the steel surface but along different bonding reaction layers.

More detailed investigations on the fractured surfaces from the tensile shear test for 
GI steel/aluminum alloy joints using SEM/EDS are shown in Fig. 12 and Table 4. At first glance, the fractured surfaces of AR-GI specimens look like a brittle fracture, while the fractured surfaces of SB5-GI specimens look like a mixture of brittle and ductile fractures. These are a bit weird if we recall that AR-GI specimens exhibited a higher bonding strength than SB5-GI specimens in Fig. 7. In the case of AR-GI specimens (Fig. 12a), a smooth brittle cleavage fracture was observed on both steel- and aluminum-sides fracture surfaces. From the EDS measurement, a significant amount of $\mathrm{Al}$ was detected on the steel-side fracture surface and in reverse, a significant amount of Fe on the aluminum-side fracture surface. It is interesting to note that $\mathrm{Zn}$ was not detected on both fracture surfaces. Taking into account lustrous surface and fracture mode together with EDS analysis results, it seems that the fracture occurred through the bonding reaction layer and brittle bonding reaction layers were composed of intermetallic compounds, $\mathrm{Al}-\mathrm{Fe}$ binary or $\mathrm{Al}-\mathrm{Fe}-\mathrm{Si}$ ternary intermetallic phases. The protruded areas of the steel-side surface and the recessed areas of the aluminum-side surface were characterized by relatively lower Si compositions than the flat areas. That is, the Si composition within the bonding reaction layer increased as the distance from the steel matrix increased. In the case of SB5-GI specimens (Fig. 12b), both a rough surface resembling ductile failure and a stepped trans-granular cleavage of a typical brittle failure were observed. In the stepped cleavage fracture area, a number of microcracks were observed and were marked by the white arrow, implying a brittle characteristic of the bonding reaction layer. Very large cracks were also observed and were marked by the double white arrow in the edge of low altitude cleavage plane on the aluminum-side surface. Large cracks seem to be due to the spalling of brittle 
bonding reaction layers over a large area. The EDS analysis on the cleavage planes represented a high $\mathrm{Al}$ composition on the steel-side surface and a high Fe composition on the aluminum-side surface, suggesting that brittle intermetallic phases formed over the steel/aluminum interface. The EDS measurement on the rough areas of the steel-side fracture surface revealed that there were two types of rough fracture surfaces. In point 6 , the elemental $\mathrm{Al}$ and $\mathrm{Si}$ were not detected at all, while in point 7, the elemental $\mathrm{Fe}$ was not detected at all. It means that the fracture occurred not only through intermetallic compound layers but also through steel substrates and aluminum alloy matrices.

In order to further get the phase information on bonding reaction products, XRD from steel- and aluminum-sides fracture surfaces were analyzed and summarized in Fig. 13. In addition to $\mathrm{Al}$ and $\mathrm{Fe}$ peaks, the peaks corresponding to $\mathrm{Fe}-\mathrm{Al}$ binary and $\mathrm{Fe}-\mathrm{Al}-\mathrm{Si}$ ternary intermetallic compounds such as $\mathrm{Al}_{5} \mathrm{Fe}_{2}, \mathrm{Al}_{13} \mathrm{Fe}_{4}, \mathrm{Al}_{8} \mathrm{Fe}_{2} \mathrm{Si}$, and $\mathrm{Al}_{4.5} \mathrm{FeSi}$ were detected and $\mathrm{Si}$ phase as well. The peaks corresponding to $\mathrm{Fe}-\mathrm{Al}-\mathrm{Zn}$ ternary intermetallic phases were not observed. However, the fact that the peaks corresponding to $\mathrm{Al}_{5} \mathrm{Fe}_{2}, \mathrm{Al}_{13} \mathrm{Fe}_{4}, \mathrm{Al}_{8} \mathrm{Fe}_{2} \mathrm{Si}$, and $\mathrm{Al}_{4.5} \mathrm{FeSi}$ phases overlap each other made it difficult to exactly identity what the kind of bonding reaction products were. The peaks of the Fe and $\mathrm{Al}$ also overlapped each other except the main peak of $\mathrm{Al}$ corresponding to (111) plane. Nevertheless, what was clear and interesting was that the main peak of $\mathrm{Al}$ and any kinds of peaks corresponding to intermetallic compounds were not detected on the steel-side facture surface of AR specimen. It is likely that in some interfacial areas of the sandblasted specimens, the effect of mechanical grip generated between the rough steel surface and the aluminum alloy by solidification shrinkage was strong enough to exceed the fracture strength of the aluminum alloy so that the crack propagated through the aluminum matrix and thus some parts of the aluminum alloy stuck to the steel 
surface as like point 7 of Fig. 12b. This is the reason why the aluminum peaks were not observed in the steel-side XRD pattern of the un-sandblasted specimen, while those were observed in the steel-side XRD patterns of the sandblasted specimens. On the other hand, what the intermetallic compounds observed over the whole steel-side facture surface of the AR-GI specimen in the OM and SEM/EDS examinations (Fig. 11, Fig. 12 and Table 4) were not detected in the XRD pattern was because the bonding reaction layer thickness stuck to the steel side was too thin to be detected., which will be illustrated in Fig. 15 of the next section.

\subsection{Characterization of the interfacial microstructure}

In order to gain a better insight into the fracture behavior of cast-bonded GI steel/aluminum alloy joints according to sandblasting surface pretreatment, crosssectional microstructures of interfacial areas were investigated by SEM (BSE) imaging and EDS spot and line scanning analyses. Fig. 14 shows low-magnification SEM (BSE) images of cross-sectional microstructures of as-cast-bonded joints with sandblasting level. The sandblasting pretreatment was observed to spur the growth of intermetallic compound phases, i.e. the average reaction layer thickness increased from about $10 \mu \mathrm{m}$ up to $40 \mu \mathrm{m}$ as the sandblasting time increased from $0 \mathrm{sec}$ to $30 \mathrm{sec}$. The reaction layer of the AR-GI specimen was thin and uniform over whole area, as shown in Fig. 14a. The morphology of the reaction layer was characterized by a flat interface on the side facing the steel matrix and by a fine spiky shape on the side facing the aluminum matrix. It has been reported that such a fine spiky intermetallic phase, frequently $\mathrm{Al}_{13} \mathrm{Fe}_{4}$ in the literature, formed when the diffusion of $\mathrm{Fe}$ atoms was limited by a continuous $\mathrm{Al}_{5} \mathrm{Fe}_{2}$ 
phase layer and/or rapid cooling rate $[28,29]$. It has been reported that the diffusion coefficient of $\mathrm{Fe}$ atoms in $\mathrm{Al}_{5} \mathrm{Fe}_{2}$ phase is very low [8]. The reaction layers of sandblasted specimens were thick and uneven in thickness, as shown in Figs. 14b and c. In these cases, the fine spiky shape morphology was not observed on the aluminum bound interface. Large cracks propagating through the thick reaction layer were frequently observed as marked by white arrow in Fig. 14c and small cracks were occasionally observed in the vicinity of the steel bound interface as marked by white arrow in Fig. 14b. On the other hand, in both sandblasted and un-sandblasted specimens, a typical finger- or tongue-like morphology of the reaction layer protruding into the steel substrate was not observed. In various joining processes of Fe/Al bimetals, the $\mathrm{Al}_{5} \mathrm{Fe}_{2}$ phase has been reported to be the most prevailing intermetallic phase and to grow irregularly into the steel substrate, forming a finger- or tongue-like morphology $[9,16,19,28-32]$. The reasons have been explained by the facts that the $\mathrm{Al}_{5} \mathrm{Fe}_{2}$ phase forms earlier than the other intermetallic phases because of its smaller Gibbs free energy than other intermetallic phases, and that the $\mathrm{Al}_{5} \mathrm{Fe}_{2}$ phase grows rapidly along its $\mathrm{c}-$ axis with a highly open structural arrangement of atoms causing aluminum atoms to diffuse much more rapidly inward [33-35]. In the present study, a low reaction temperature and short reaction time of the compound casting process coupled with a high Si content of the aluminum alloy seems to have influenced on the bonding reaction, resulting in morphological changes.

In order to identify the microstructural phase of the interfacial bonding zone and explore the fracture mechanism, more detailed observations and compositional examinations were carried out, as shown in Fig. 15, Fig. 16, and Table 5. The higher 
magnification SEM (BSE) images of Fig. 15 revealed that interfacial reaction layers were seemingly distinguished into three layers according to the gray level. Cracks were observed in different locations according to the sandblasting pretreatment time. As the distance from the steel-bound interface increased into the aluminum direction, the gray color became darker and darker, which means the gradual decrease of Fe compositions. EDS analysis results of Table 5 revealed that the Fe content gradually decreased while the Si content steadily increased as the distance from the steel-bound interface increased in the aluminum direction. Taking into account XRD and SEM/EDS results and thermodynamic equilibrium data reactions [13-15], it was suggested that the reaction zone mainly consisted of three intermetallic compounds layers; directly adjacent to the steel substrate was $\mathrm{Al}_{13} \mathrm{Fe}_{4}$ phase, a intermediate layer was $\mathrm{Al}_{8} \mathrm{Fe}_{2} \mathrm{Si}$ phase, and an outer layer adjacent to the aluminum matrix was $\mathrm{Al}_{4.5} \mathrm{FeSi}$ phase. The chemical compositions analyzed by SEM/EDS coincided well with the stoichiometric $\mathrm{Al}$ to $\mathrm{Fe}$ ratios of $\mathrm{All}_{3} \mathrm{Fe}_{4}$, $\mathrm{Al}_{8} \mathrm{Fe}_{2} \mathrm{Si}$ and $\mathrm{Al}_{4.5} \mathrm{FeSi}$ phases, while the silicon contents in the all intermetallic compound layers were detected somewhat higher than their stoichiometric compositions due to some Si phase particles. These interfacial Si phases seem to have been formed by two reactions. First, the Si phase can be formed together by a pseudo peritectic reaction when the $\mathrm{Al}_{4.5} \mathrm{FeSi}$ phase is formed $[13,15]$. Second, they also can be formed as the primary phase in a $\mathrm{Zn}$-rich solution in the process of dissolution of the $\mathrm{Zn}$ coating into the aluminum melt, which will be explained later in the next chapter. And it was noticeable that the elemental $\mathrm{Zn}$ was hardly detected this time also as in the fractographical SEM/EDS analysis of Fig. 12 and Table 4. The elemental distributions were also confirmed in the EDS line scan results across the bonding interface of the AR -GI specimen, as shown in Fig. 16. The elemental $\mathrm{Zn}$ was detected only as the 
background fluctuations of noise level, which implies that it was diluted inside the aluminum matrix. And the EDS line scan results revealed that the elemental $\mathrm{Al}$ and $\mathrm{Si}$, being present in the bonding reaction layer, hardly diffused into the steel substrate with a flat interface, while the elemental Fe clearly diffused into the aluminum matrix with an irregular interface. The Si peaks detected inside the reaction layer, in front of the aluminum-bound interface and in the aluminum matrix appeared to be attributed to the crystallization of $\mathrm{Si}$ phase by the above mentioned pseudo pretiectic and primary crystallization reactions. However $\mathrm{Si}$ is similar in density to $\mathrm{Al}$, thus is hardly distinguished from the aluminum matrix in SEM (BSE) images.

According to phase equilibria data [13-15], $\mathrm{Al}-\mathrm{Fe}$ and $\mathrm{Al}-\mathrm{Fe}-\mathrm{Si}$ intermetallic compound phases such as $\mathrm{Al}_{5} \mathrm{Fe}_{2}, \mathrm{Al}_{13} \mathrm{Fe}_{4}, \mathrm{Al}_{8} \mathrm{Fe}_{2} \mathrm{Si}$, and $\mathrm{Al}_{4.5} \mathrm{FeSi}$ can be formed successively in steel(solid)/Al-Si aluminum alloy(liquid) bonding zones through several peritectic reactions. And it has been reported that during hot-dip galvanizing and compound casting of $\mathrm{Al}-\mathrm{Si}$ alloy/zinc-coated steel, the $\mathrm{Zn}$ atoms substitute for $\mathrm{Fe}$ atoms of those intermetallic compound phases, resulting in the formation of $\mathrm{Zn}$ containing phases such as $\mathrm{Al}_{5} \mathrm{Fe}_{2} \mathrm{Zn}_{x}, \mathrm{Al}_{3} \mathrm{FeZn}_{x}, \mathrm{Al}_{8}(\mathrm{Fe}, \mathrm{Zn})_{2} \mathrm{Si}$, and $\mathrm{Al}_{5}(\mathrm{Fe}, \mathrm{Zn}) \mathrm{Si}$ [14]. However, in the present research, the $\mathrm{Al}_{5} \mathrm{Fe}_{2}$ phase, which has been reported as the most prevailing phase in most aluminum/steel bimetal joining processes including welding, immersion, diffusion bonding, and compound casting, was not detected. Also the $\mathrm{Al}_{5} \mathrm{Fe}_{2} \mathrm{Zn}_{x}$ phase was not detected. The actual formation of intermetallic compound with complex super lattice structures is influenced by various conditions. It has been reported that when dissimilar metals come into contact, the formation of the intermetallic compound phases depend on many factors such as the chemical potentials, nucleation conditions, 
mobilities of the constituent elements, and alloys compositions [13,36]. In addition, the reaction temperature and time of bonding processes appear to have a significant effect on the formation of intermetallic phases.

In welding, diffusion bonding, and immersion tests, the $\mathrm{Al}_{5} \mathrm{Fe}_{2}$ phase has been reported to form first at the steel/aluminum interface as the major reaction layer with the thickest thickness $[9,16,19,28-32]$. The weld pool temperature reaches over $1,200^{\circ} \mathrm{C}$ during welding [5]. According to $\mathrm{Al}-\mathrm{Fe}$ phase diagram [37], it is higher than the liquidus temperature of $\mathrm{Al}_{5} \mathrm{Fe}_{2}$-liquid equilibria region, 1,157 to $1,171^{\circ} \mathrm{C}$. It is likely that a high heat input of welding processes allows a large amount of $\mathrm{Fe}$ atoms to dissolve into weld pools. Then when weld pools cools down to the $\mathrm{Al}_{5} \mathrm{Fe}_{2}$-liquid equilibria temperature range, $\mathrm{Fe}$ atoms reach the super-saturation level, resulting in the formation of $\mathrm{Al}_{5} \mathrm{Fe}_{2}$ phase at the steel/aluminum interface. In the cases of immersion and diffusion bonding, although the process temperatures are pretty lower than the $\mathrm{Al}_{5} \mathrm{Fe}_{2}$-liquid equilibria temperature, process times are long enough so that the $\mathrm{Fe}$ atoms sufficiently may diffuse into the steel and accumulate at the interface $[16,19,28,29]$. As a result, finger-like shape $\mathrm{Al}_{5} \mathrm{Fe}_{2}$ phase layers can be formed by a solid state phase transformation. The formation of $\mathrm{Al}_{5} \mathrm{Fe}_{2}$ phases has been also reported in compound casting processes which were carried out at a lower temperature in comparison to welding during a shorter time in comparison to diffusion bonding and immersion processes. Viala [15], Bouayad et al. [18] reported that three intermetallic compound layers of $\mathrm{Al}_{5} \mathrm{Fe}_{2}, \mathrm{Al}_{8} \mathrm{Fe}_{2} \mathrm{Si}$, and $\mathrm{Al}_{4.5} \mathrm{FeSi}$ phases were sequentially formed from the cast iron bound interface toward the $\mathrm{Al}-\mathrm{Si}$ aluminum alloy matrix. However, in these studies, it is likely that the $\mathrm{Al}_{5} \mathrm{Fe}_{2}$ phase already formed during aluminizing 
process in which cast iron inserts were immersed into molten aluminum bath at $780^{\circ} \mathrm{C}$ for $4 \mathrm{~min}$ prior to the compound casting process. It might have been difficult to distinguish the $\mathrm{Al}_{5} \mathrm{Fe}_{2}$ phase formed during the aluminizing process from that formed during compound casting processes. In Jiang et al's study on the compound casting of a zinc-coated steel and an $\mathrm{Al}-7 \% \mathrm{Si}$ alloy [13], only the $\mathrm{Al}_{4.5} \mathrm{FeSi}$ phase was observed in bonding interface and other intermetallic phases were not observed. They explained that the reason is that the formation of intermetallic phases could be influenced by many factors including alloys compositions. Actually, Cheng et al's immersion testing study [19] on the interaction between solid steel and molten aluminum alloy revealed that as the Si content increased, the thickness of $\mathrm{Al}_{5} \mathrm{Fe}_{2}$ phase layer significantly decreased while the thickness of $\mathrm{Al}_{13} \mathrm{Fe}_{4}$ phase layer slightly decreased and the $\mathrm{Al}_{5} \mathrm{Fe}_{2} /$ steel interface changed from a tongue-like into a flat morphology. The possibilities of the subsequent phase transformation to other intermetallic compounds after bonding process have been reported: according to Bouayad et al. [18], the $\mathrm{Al}_{13} \mathrm{Fe}_{4}$ phase was transformed to the $\mathrm{Al}_{8} \mathrm{Fe}_{2} \mathrm{Si}$ and $\mathrm{Al}_{4.5} \mathrm{FeSi}$ phases during the cooling process following the compound casting. In addition, the process characteristics of compound casting, i.e. its lower process temperature and shorter process time in comparison to the other bimetallic bonding processes, seem to have an influence on the interfacial metallurgical reactions, resulting in the tendency that the $\mathrm{Al}_{5} \mathrm{Fe}_{2}$ phase is hardly observed in the steel/aluminum interface. According to $\mathrm{Al}-\mathrm{Fe}$ phase diagram [37], the temperature range of $700 \sim 750^{\circ} \mathrm{C}$, at which the compound casting of steel/aluminum bimetals was generally performed, belongs to the $\mathrm{Al}_{13} \mathrm{Fe}_{4}$-liquid equilibrium region. That is, it is likely that less amount of $\mathrm{Fe}$ atoms dissolve into molten aluminum alloys in comparison 
to welding, and then when molten aluminum alloys cool down to the liquidus line of the $\mathrm{Al}_{13} \mathrm{Fe}_{4}$-liquid equilibria region, the $\mathrm{Fe}$ atoms reaches the super-saturation level, resulting in the formation of $\mathrm{Al}_{13} \mathrm{Fe}_{4}$ phase at the steel/aluminum interface. On the other hand, another study on the compound casting of a zinc-coated steel and an $\mathrm{Al}-0.4 \% \mathrm{Si}$ alloy by Liu et al reported the formation of the $\mathrm{Al}_{5} \mathrm{Fe}_{2} \mathrm{Zn}_{x}$ phase: the interfacial bonding zone consisted of a continuous $\mathrm{Al}_{5} \mathrm{Fe}_{2} \mathrm{Zn}_{x}$ layer in contact with the steel substrate, an intermediate layer of $\mathrm{Al}_{8}(\mathrm{Fe}, \mathrm{Zn})_{2} \mathrm{Si}$ and outer discontinuous needle-like $\mathrm{Al}_{5}(\mathrm{Fe}, \mathrm{Zn}) \mathrm{Si}$ phases [14]. They also mentioned the possibility that a part of diffusion layer, which was formed during galvanizing process and consisted of $\mathrm{Al}_{5} \mathrm{Fe}_{2} \mathrm{Zn}_{x}$ and $\mathrm{Al}_{13} \mathrm{Fe}_{4} \mathrm{Zn}_{x}$ phases, did not dissolve during compound casting and remained as part of the final interfacial bonding layer. The Si content of the aluminum alloy in Liu's study [14] was much lower compared to one in Jiang et al's study [13]. Based on these considerations, it can be concluded that in the present study, a low reaction temperature and short reaction time of the compound casting process coupled with a high $\mathrm{Si}$ content of the aluminum alloy kept the $\mathrm{Al}_{5} \mathrm{Fe}_{2}$ phase from forming and growing, and instead led to the formation of the subsequent low temperature phases such as $\mathrm{Al}_{13} \mathrm{Fe}_{4}, \mathrm{Al}_{8} \mathrm{Fe}_{2} \mathrm{Si}$, and $\mathrm{Al}_{4.5} \mathrm{FeSi}$.

Cracks were observed to be formed in different locations according to the sandblasting pretreatment. In steel/aluminum bimetals, the interfacial bonding zone is definitely the most susceptible to cracking, because it is composed of brittle intermetallic phases and also a large thermal stress is generated there due to a large difference of thermal expansion coefficients between the aluminum and the steel. The sandblasting pretreatment seemed to spur the growth of intermetallic phase layer, resulting in the shift of prevailing cracking sites. It was shifted from the $\mathrm{Al}_{13} \mathrm{Fe}_{4}$ layer in 
contact with the steel substrate to the intermediate $\mathrm{Al}_{8} \mathrm{Fe}_{2} \mathrm{Si}$ layer and the inside of the steel near the bonding interface. In the un-sandblasted specimens, cracks were observed to propagate mainly along the thin $\mathrm{Al}_{13} \mathrm{Fe}_{4}$ layer adjacent to the flat steel substrate interface, as shown in Fig. 15a. This is the reason why even though the steel-side fracture surface of $\mathrm{AR}-\mathrm{GI}$ specimens showed intermetallic characteristics in $\mathrm{OM}$ and SEM/EDS examinations (Fig. 11a and Fig. 12a), any intermetallic compounds peaks were not detected in the XRD analysis (Fig. 13a). Such a thin thickness of bonding reaction layer stuck to the steel side seems to have been hardly detected in the XRD analysis. Since the bonding reaction layer was thin and uniform in thickness over the whole area, it is presumed that the steel interface containing pre-existing defects such as oxides was the region most vulnerable to cracking. On the other hand, in the sandblasted specimens, as oxide defects were removed by sandblasting and the brittle intermetallic phase layers became thicker and uneven, the thick intermediate $\mathrm{Al}_{8} \mathrm{Fe}_{2} \mathrm{Si}$ layer seems to have served the sites for stress concentration and crack initiation. Crack clusters were observed in wide band form inside the $\mathrm{Al}_{8} \mathrm{Fe}_{2} \mathrm{Si}$ layer, as marked by white dashed lines on Fig. 15c. These crack clusters appear to be responsible not only for the spalling of bonding reaction layer observed on the fracture surface of Fig. 12b but also for the large cracks propagating through the bonding reaction layer of the cross-section microstructure of Fig. 14c. And interestingly, in the sandblasted specimens, cracks were frequently observed at the shallow region inside the steel substrate in the vicinity of the bonding interface, as marked by the double white arrow on Figs. 15b and c. Also, in the steel near the bonding interface, a large amount of pores were observed, as marked by the white arrow. These pores are believed to be Kirkendall voids resulting from unbalanced diffusion rates between $\mathrm{Al}$ and $\mathrm{Fe}$ atoms at the steel/aluminum interface. It 
is likely that the residual thermal stress and external stress were locally concentrated at these pores, causing the crack initiation. The rough areas of the steel-side fracture surface of the SB30-GI specimen (point 6 on Fig. 12b), at which Al and Si elements were not detected at all form the EDS analysis, seem to have been generated by the cracks developed form the Kerkendall voids. On the other hand, the location of Kerkendall voids is in contrast to others' reports $[15,29,36]$ that in Fe/Al bimetallic systems, Kerkendall voids were generally formed on the aluminum side. In those reports, the Kerkendall voids seem to have been generated mainly as by-products of solid-state diffusion controlled reactions, i.e. the inter-diffusion process or the annealing process after friction stir welding or compound casting. Al atoms diffuse much more rapidly through the $\mathrm{Al}_{5} \mathrm{Fe}_{2}$ phase, which is formed directly adjacent to the steel substrate as the most prevalent phase in Fe/Al bimetallic systems, than $\mathrm{Fe}$ atoms $[19,39]$. By contrast, in this study, the dissolution rate of Fe atoms into the molten aluminum alloy was much higher than one of $\mathrm{Al}$ atoms into the solid steel substrate. Thus vacancies moved toward the steel side, resulting in the formation of Kerkendall voids at the steel substrate close to the bonding interface. In addition, a high Si content of the aluminum alloy and the absence of the $\mathrm{Al}_{5} \mathrm{Fe}_{2}$ phase also seem to have had some influences on the location of Kerkendall voids.

\section{5 $\mathrm{Zn}$ coating behavior and its effect on interfacial microstructure evolution}

The main purpose of $\mathrm{Zn}$ coating on steels is known to keep surfaces from being oxidized. Thus, in aluminum/steel bimetal joining processes, it plays roles in the removal of oxidation scale of the steel insert and the improvement of the wettability between the aluminum and the steel, promoting the metallurgical bonding reaction [13]. 
Liu [14] and Jia et al. [39] reported that the ductility of the intermetallic layers was able to be improved when the $\mathrm{Zn}$ atoms substituted for $\mathrm{Fe}$ atoms of $\mathrm{Al}_{5} \mathrm{Fe}_{2}$ and $\mathrm{Al}_{13} \mathrm{Fe}_{4}$ phases and led to the formation of $\mathrm{Al}_{5}(\mathrm{Fe}, \mathrm{Zn})_{2}$ and $\mathrm{Al}_{13}(\mathrm{Fe}, \mathrm{Zn})_{4}$ phases. It has been reported that the $\mathrm{Zn}$ coating accelerated the growth of intermetallic phases and thus caused an excessive formation of intermetallic phase layers [29]. However, this is somewhat in contradiction with the present experiment results. In the present study, the thickness of intermetallic phase layer increased as the thickness of residual $\mathrm{Zn}$ coating layer decreased (Fig. 14). It is observed that $\mathrm{Zn}$ coatings on steel surfaces have many beneficial influences on aluminum/steel bimetal joining characteristics. However, interestingly, many studies on aluminum/steel joining except diffusion bonding processes as well as the present study have reported that $\mathrm{Zn}$ atoms are hardly detected at interfacial intermetallic phases $[12,13,28,39]$. The reasons for that are tried to be explained in relation to the behavior of $\mathrm{Zn}$ coating layer as follows. In welding processes of zinc-coated steels and aluminum alloys, a portion of $\mathrm{Zn}$ coating was dissolved into Al melts [39] and the rest was evaporated due to much higher weld pool temperatures than the $\mathrm{Zn}$ boiling temperature $\left(907^{\circ} \mathrm{C}\right)[4,10,28]$ or pushed by the arc jet or by the higher chemical affinity of $\mathrm{Al}-\mathrm{Fe}$ than that of $\mathrm{Zn}-\mathrm{Fe}$, resulting in the accumulation at the weld toes $[5,10,40]$. In the case of compound casting, the whereabouts of $\mathrm{Zn}$ coating layer was unclear: on compound casting of $\mathrm{Al}-0.4 \% \mathrm{Si}$ alloy and zinc-coated steel with $300 \mu \mathrm{m}$ thick $\mathrm{Zn}$ coating, $\mathrm{Zn}$ atoms were observed in the interfacial intermetallic phases [14], while using $\mathrm{Al}-6.8 \% \mathrm{Si}$ alloy and zinc-coated steel with $300 \mu \mathrm{m}$ thick $\mathrm{Zn}$ coating, $\mathrm{Zn}$ atoms were not observed in the bonding zone [13]. To simulate a compound casting process, Khoonsari et al. [12] conducted an immersion test, 
in which a zinc-coated steel with $25 \mu \mathrm{m}$ thick $\mathrm{Zn}$ coating was immersed into an $\mathrm{Al}-$ $6 \% \mathrm{Si}$ alloy melt of $720^{\circ} \mathrm{C}$ for $10 \mathrm{~min}$ and removed from furnace followed by solidification, and raised two possibilities as the reason for the absence of $\mathrm{Zn}$ atoms at the interface, i.e., the $\mathrm{Zn}$ atoms were homogeneously dissolved into the $\mathrm{Al}$ melt and/or evaporated from the bath. However, it appears that the immersion time was too long to simulate actual casing processes and the melt temperature was too low to evaporate zinc.

In order to investigate the $\mathrm{Zn}$ coating behavior during compound casting process and its effects on the interfacial microstructure evolution and the fracture mechanism, quenching experiments were carried out. Fig. 17 shows the cross-sectional SEM (BSE) image of the interfacial areas of quenched AR-GI specimens, which were obtained by quenching into water immediately after pouring the molten aluminum on the unsandblasted GI steels. Bright color areas on the micrographs correspond to $\mathrm{Zn}$ rich zones. The chemical composition analyzed by EDS is summarized in Table 6. A variety of microstructures caused by different solidification rates were obtained depending on specimens and sampling locations. Fig. 17a shows a frozen $\mathrm{Zn}$ region in a shape almost similar to the original $\mathrm{Zn}$ coating layer before melting. In Fig. 17b, hemisphere-like Znrich zones are shown. Even although the Zn content slightly decreased with going to outer periphery, the hemispherical areas proved to be a $\mathrm{Zn}$-rich solution containing very small amount of $\mathrm{Al}$ and $\mathrm{Si}$ atoms. The quenched microstructure adjacent to the steel interface consisted of $\eta-\mathrm{Zn}$ and primary $\mathrm{Si}$ phases (points 2 and 5 on Fig. 17b, respectively). Because the $\mathrm{Zn}-\mathrm{Al}-\mathrm{Si}$ ternary eutectic point is extremely skewed to the Zn-rich corner $(94.95 \% \mathrm{Zn}-5 \mathrm{Al}-0.05 \% \mathrm{Si})$ [41], the $\mathrm{Si}$ was crystallized as the primary phase in spite of a high $\mathrm{Zn}$ composition of $\mathrm{Zn}-\mathrm{Al}-\mathrm{Si}$ solution. The quenched 
microstructure of outer periphery of the hemisphere consisted of $\alpha-\mathrm{Al}$ and $\mathrm{Zn}-\mathrm{Al}-\mathrm{Si}$ eutectic phases (points 4 and 3 on Fig. 17b, respectively). Considering that the Al composition of the $\alpha-\mathrm{Al}$ cell core was $76 \mathrm{wt} \%$, it was deduced from the phase diagram that the $\mathrm{Zn}$ content of the outer periphery of the hemisphere probably reached $89 \mathrm{wt} \%$ or more before quenching. It is likely that when the aluminum melt was poured on the zinc-coated steel, the $\mathrm{Zn}$ coating layer melted, and then not only diffused into the aluminum melt but also spheroidized as well. The spheroidization of molten $\mathrm{Zn}$ can be explained by a higher chemical affinity of $\mathrm{Al}-\mathrm{Fe}$ than that of $\mathrm{Zn}-\mathrm{Fe}[5,10,40]$ and a typical characteristic of liquid phase tending to reduce its surface area for the reduction of the surface energy. The quenched microstructure shown in Fig. 17c revealed that the dissolution of $\mathrm{Zn}$ atoms into the $\mathrm{Al}$ melt was further advanced. The $\eta-\mathrm{Zn}$ and primary $\mathrm{Si}$ phases disappeared, while the primary $\alpha-\mathrm{Al}$ and $\mathrm{Al}-\mathrm{Zn}-\mathrm{Si}$ eutectic phases were observed even at the region close to the steel interface. It is noticeable that a discontinuous intermetallic compound layer, probably the $\mathrm{Al}_{13} \mathrm{Fe}_{4}$ phase, protruding toward the aluminum matrix was formed. Fig. $17 \mathrm{~d}$ shows the microstructure in which the $\mathrm{Zn}$ atoms of coating layer almost fully dissolved into the aluminum matrix. A continuous intermetallic compound layer of very fine spiky shape extending into the aluminum matrix was formed, and a substantially $\mathrm{Zn}$-free intercellular microstructure was observed. The white color phases in intercellular area were not the $\mathrm{Al}-\mathrm{Zn}-\mathrm{Si}$ eutectic phases but $\mathrm{Al}-\mathrm{Fe}-\mathrm{Si}$ ternary intermetallic compounds. These quenched microstructural examinations suggested that the steel interface was very quickly exposed to substantially $\mathrm{Zn}$-free aluminum melt with the help of micro scale fluid flow causing spheroidization, probably much faster than atomic scale diffusion, and caused 
the absence of $\mathrm{Zn}$ at the steel/aluminum interfacial intermetallic phases.

Based on our experimental findings, theoretical considerations, and literature data, the behavior of $\mathrm{Zn}$ coating layer and the related microstructural evolution at the interfacial bonding area during the compound casting process of zinc-coated steel/aluminum alloy are summarized with the schematic illustrations of Fig. 18. When the molten aluminum alloy with higher melting point than the zinc is poured into the mold with the GI steel insert, the $\mathrm{Zn}$ coating layer melts and then rapidly disappears from the steel surface not only due to atomic scale diffusion but also due to micro scale fluid flow driven by spheroidizaton for reducing surface energy as well as a higher chemical affinity between $\mathrm{Al}$ and Fe (Fig. 18a-i and ii). As a result, the steel surface speedily comes into contact with a substantially $\mathrm{Zn}$-free aluminum melt, and Fe atoms dissolves into the aluminum melt, and eventually the $\mathrm{Zn}$-free $\mathrm{Al}_{13} \mathrm{Fe}_{4}$ phase forms on the steel surface when Fe atoms reach the super-saturation because of the increase of $\mathrm{Fe}$ dissolution amount and/or the decrease of the melt temperature (Fig. 18a-iii). A low reaction temperature and short reaction time of the compound casting process coupled with a high $\mathrm{Si}$ content of the aluminum alloy give the $\mathrm{Al}_{13} \mathrm{Fe}_{4}$ phase an advantage as the primary phase over the $\mathrm{Al}_{5} \mathrm{Fe}_{2}$ phase. Afterwards, the intermediate $\mathrm{Al}_{8} \mathrm{Fe}_{2} \mathrm{Si}$ layer and the finely spiky outer $\mathrm{Al}_{4.5} \mathrm{FeSi}$ layer protruding toward the aluminum matrix are successively formed by peritectic solidification reactions (Fig. 18a-iv and v). The Zn coating of the GI steel plays a role to improve the wettability and reactivity between the steel substrate and the aluminum melt by keeping the steel surface from oxidation during transportation, handling, preheating etc., but also to delay the initiation of interfacial bonding reaction due to, albeit short, its disappearing time, resulting in the thin and uniform intermetallic compounds layers. In the case of the GA steels, thick and 
stable oxide scales, which are formed on the $\mathrm{Zn}$ coating surface by thermal oxidation during the galva-annealing treatment, hardly disappear under casting conditions and impedes the dissolution of the $\mathrm{Zn}$ coating layer into the molten aluminum, leading to the prevention of the direct contact between the molten aluminum and the steel surface and the subsequent metallurgical bonding reaction. On the other hand, the sandblasting pretreatment makes the $\mathrm{Zn}$ coating layer thin and exposes a considerable portion of fresh steel surface, where pre-existing defects such as oxide scale are also removed (Fig. 18b-i). As a result, the GI steel surface contacts with the aluminum melt earlier than the non-sandblast case, resulting in a higher Fe elemental super-saturation level and faster bonding reaction initiation at a higher temperature (Fig. 18b-ii) and consequentially thicker intermetallic compounds layers with an outer layer of relatively blunt morphology (Fig. 18b-v). The growth of intermetallic compounds is further spurred at the areas where an oxide-free fresh steel matrix is exposed, resulting in intermetallic compounds layers having a non-uniform thickness distribution. An excessive formation of intermetallic compounds generates Kirkendall pores, resulting from the unbalanced diffusion rates between $\mathrm{Al}$ and $\mathrm{Fe}$ atoms, at the shallow region inside the steel substrate near the bonding interface (Fig. 18b-iv). When a large residual thermal stress is generated during compound casting process due to a large thermal expansion coefficient difference between steels and aluminums or further an external stress is additionally applied, cracks are initiated at the Kirkendall pores as a result of stress concentrations and micro crack clusters are formed at thick parts of the intermediate $\mathrm{Al}_{8} \mathrm{Fe}_{2} \mathrm{Si}$ layer as well. The propagation of fracture along such two kinds of interfacial defects leads to a rough fracture surface morphology with lower interfacial bonding strength, while a smooth fracture surface morphology with higher interfacial bonding strength is 
observed in the non-sandblast specimen.

The results of this investigation suggest that, in order to achieve the structural integrity of steel/aluminum bimetal with a high interfacial bonding strength by compound casting, the thickness of interfacial intermetallic phase layers and the thermal stress need to be properly controlled, and this requires optimizing of the $\mathrm{Zn}$ coating thickness and preheating of the steel inserts. It is needed to recall that in sandblasted specimens, although the mechanical grip which was stronger than the aluminum matrix strength was locally generated between the rough steel surface and the aluminum alloy by solidification shrinkage (Fig. 12b and 13a), cracks which were formed at the interfacial reaction area in as-cast-bonded state due to an excessive formation of intermetallic phases (Fig. 14c and Fig. 15b and c) rather decreased the interfacial bonding strength to less than that of un-sandblasted specimens (Fig. 7). Such a situation would be more worsened in the case of layered type bimetals with a large joining area, which are more vulnerable to de-bonding compared to embedded type bimetallic parts, the thickness of interfacial intermetallic compound layers and the thermal stress must be minimized. The preheating of insert metals is beneficial to reduce the thermal stress generated between the steel and the aluminum alloy due to a large difference of thermal expansion coefficients. Also the insert preheating is important in terms of preventing the surface defects such as pinholes, blowholes etc. caused by gas [42], and securing the reaction energy for interfacial bonding in compound casting, which is a bonding process with relatively low heat input and large bonding area in comparison to the welding processes. On the other hand, the $\mathrm{Zn}$ coating can effectively keep the steel inserts from surface oxidation during preheating, and also can serve as another vital factor to control the interfacial bonding reaction rate. That is, the fast disappearing behavior of the $\mathrm{Zn}$ 
coating layer caused by the combination of atomic scale diffusion and micro scale fluid flow not only keeps the reactivity between steel inserts and molten aluminum alloy good but also delays the initiation of interfacial bonding reaction, resulting in playing a role in controlling the interfacial bonding reaction rate according to the initial $\mathrm{Zn}$ coating thickness (Fig. 14 and 17). Steel/aluminum bimetal systems are known to have a narrow processing window for bonding: they are hard to be metallurgically bonded because of the high steel surface oxidation tendency and the much different thermalphysical properties between those two metals, but once the energy input is high enough to ignite the metallurgical bonding reaction, it is difficult to avoid an excessive formation of brittle interfacial reaction layer due to the rapid growth kinetics of intermetallic phases $[12,13,29]$. In addition, controlling the bonding reaction rate only by the superheat temperature of aluminum alloy melt may cause another problem, i.e., too high superheat temperature creates the aluminum alloy melt oxidation, porosity defects, etc., and in revere, too low superheat temperature makes it difficult to cast complex shaped parts with large area and various casting thickness, especially thin casting section. The thin wall fluidity, which meant the flow length of aluminum alloy melt in a thin cavity formed by the zinc-coated steel insert and the mold wall, was mainly dependent on the surface roughness of the zinc-coated steel insert rather than the wettability (Figs. 5, 8 and 9). In these circumstances, it seems that the compound casting process using the commercial GI steels and sandblasting pretreatment is promising and economical to produce large areal layered type steel/aluminum bimetals with high structural integrity. In order to get high interfacial bonding strengths and good castability as well, it is necessary to systematically control the $\mathrm{Zn}$ coating thickness, the surface roughness, the preheating temperature of steel inserts, and the aluminum alloy 
melt superheat temperature by taking into account the casting section thickness and size of GI steel/aluminum bimetallic parts. In the case of GA steels, it seems to be unsuitable for the application because of thick and stable oxide scales which exist on the $\mathrm{Zn}$ coating surface and the interface between the steel matrix and the $\mathrm{Zn}$ coating layer.

\section{CONCLUSIONS}

In this study, the effects of zinc-coated steel type (DP980-GI and DP590-GA steels) and steel surface sandblasting pretreatment time $(0,5$ and $30 \mathrm{sec})$ on the solid-liquid compound casting characteristic of layered type zinc-coated steel/A356 aluminum alloy bimetals have been investigated. From the experimental results the following conclusions are drawn:

1. The flow length of the molten aluminum alloy in thin plate type flow channels formed by the steel insert and the mold wall showed an inverse relationship with the insert surface roughness caused by the sandblasting. The flow length was mainly dependent on the surface roughness and slightly dependent on the wettability proportional to residual $\mathrm{Zn}$ coating thickness.

2. Cast-bonded GI steel specimens showed the highest interfacial bonding strength in non-sandblasted conditions (more than $20 \mathrm{MPa}$ ), while GA steels were able to be cast-bonded only in the most heavily sandblasted condition and showed a low interfacial bonding strength (less than $5 \mathrm{MPa}$ ).

3. The interfacial bonding zone was mainly composed of intermetallic compounds of $\mathrm{Al}_{13} \mathrm{Fe}_{4}, \mathrm{Al}_{8} \mathrm{Fe}_{2} \mathrm{Si}$, and $\mathrm{Al}_{4.5} \mathrm{FeSi}$ phases in order from the steel interface.

4. All intermetallic compound layers showed somewhat higher silicon contents than 
their stoichiometric compositions due to interfacial Si phases, which were crystallized by the pseudo peritectic reaction and the primary crystallization reaction.

5. A low reaction temperature and short reaction time of the compound casting process coupled with a high Si content of the aluminum alloy suppressed the formation of $\mathrm{Al}_{5} \mathrm{Fe}_{2}$ phase, which is formed directly adjacent to the steel interface and is the most prevalent in many steel/aluminum joining processes.

6. The $\mathrm{Zn}$ coating of the GA steel was scarcely mixed with the aluminum melt due to oxide scales and inhibited the interfacial bonding reaction by preventing the steel surface from contacting the aluminum melt, while the $\mathrm{Zn}$ coating of the GI steel was rapidly disappeared from the steel surface by the chemical affinity- and surface energy-driven fluid flow as well as the diffusion and resulted in the formation of $\mathrm{Zn}$ free intermetallic compounds.

7. Fast disappearing behaviors of $\mathrm{Zn}$ coating of GI steels not only kept the steel/aluminum reactivity good but also retarded the onset of interfacial bonding reaction so that the rate of steel/aluminum bonding reaction having a narrow processing window was controlled by changing the thickness of $\mathrm{Zn}$ coating.

8. The sandblasting pretreatment on GI steels promoted the growth of intermetallic compounds and caused the formation of Kirkendall voids on the steel side, resulting in the shift of main fracture site from the $\mathrm{Al}_{13} \mathrm{Fe}_{4}$ layer in contact with steel substrate to the intermediate $\mathrm{Al}_{8} \mathrm{Fe}_{2} \mathrm{Si}$ layer and the inside of the steel near the bonding interface.

9. Increased crack susceptibilities, which surpassed the effect of mechanical grip generated between the rough steel surface and the aluminum alloy by solidification shrinkage, slightly lowered the bonding strength of the joints of sandblasted GI 
steel/aluminum bimetals.

\section{REFERENCES}

[1] R.W. Rudd, in: Proceedings of IRCOBI Conference 2016, Sep. 14, Malaga, Spain, 2016.

[2] J. Saunders, M. Craig, J. Suway, in: 22nd International Technical Conference on the Enhanced Safety of Vehicles, Washington, D.C., USA, 2011.

[3] H.W. Son, T.K. Jung, J.W. Lee, S.K. Hyun, Hot deformation characteristics of CaOadded AZ31 based on kinetic models and processing maps, Mater. Sci. \& Eng. A695 (2017) 379-385.

[4] M. Gatzen, T. Radel, C. Thomy, F. Vollertsen, Wetting behavior of eutectic Al-Si droplets on zinc coated steel substrates, J. Mater. Process. Technol. 214 (2014) 123131.

[5] Y. Fu, Y. Zhang, J. Jie, K. Svynarenko, C. Liang, T. Li, Interfacial phase formation of Al-Cu bimetal by solid-liquid casting method, Res. Dev. 14 (2017) 194-198

[6] W. Jiang, Z. Fan, C. Li, Improved steel/aluminum bonding in bimetallic castings by a compound casting process, J. Mater. Process. Technol. 226 (2015) 25-31.

[7] Y.C. Chen, T. Komazaki, Y.G. Kim, T. Tsumura, K. Nakata, Interface microstructure study of friction stir lap joint of AC4C cast aluminum alloy and zinc-coated steel, Mater. Chem. Phys. 111 (2008) 375-380.

[8] L. Mei, G. Chen, X. Jin, Y. Zhang, Q. Wu, Research on laser welding of highstrength galvanized automobile steel sheets, Opt. Las. Eng. 47 (2009) 1117-1124.

[9] N. Takata, M. Nishimoto, S. Kobayashi, M. Takeyama, Crystallography of Fe2Al5 phase at the interface between solid Fe and liquid Al, Intermet. 67 (2015) 1-11. 
[10] Y. Zhou, Q. Lin, Wetting of galvanized steel by Al 4043 alloys in the first cycle of CMT process, J. Alloys \& Compd. 589 (2014) 307-313.

[11] S.M. Emami, M. Divandari, E. Hajjari, H. Arabi, Comparison between conventional and lost foam compound casting of $\mathrm{Al} / \mathrm{Mg}$ light metals, Intl. J. Cast Met. Res. 26 (2013) 43-50.

[12] E.M. Khoonsari, F. Jalilian, F. Paray, D. Emadi, R.A.L. Drew, Interaction of 308 stainless steel insert with A319 aluminium casting alloy, Mater. Sci. Technol. 26 (2010) 833-841.

[13] W. Jiang, Z. Fan, G. Li, C. Li, Effects of zinc coating on interfacial microstructures and mechanical properties of aluminum/steel bimetallic composites, J. Alloys \& Compd. 678 (2016) 249-257.

[14] Y. Liu, X. Bian, K. Zhang, C. Yang, L. Feng, H.S. Kim, J. Guo, Interfacial microstructures and properties of aluminum alloys/galvanized low-carbon steel under high-pressure torsion, Mater. \& Des. 64 (2014) 287-293.

[15] J.C. Viala, M. Peronnet, F. Barbeau, F. Bosselet, J. Bouix, Interface chemistry in aluminium alloy castings reinforced with iron base inserts, Compos. : Part A 33 (2002) 1417-1420.

[16] A. Bouayad, C. Gerometta, A. Belkebir, A. Ambar, Kinetic interactions between solid iron and molten aluminium, Mater. Sci. \& Eng. A363 (2003) 53-61.

[17] Y.H. Kim, E.S. Kim, H.S. Kim, K.H. Lee, A Study on the Surface Characterization of $\mathrm{Fe}-17$ wt.\%Cr Steel for Cast-bonding of $\mathrm{Al}$ and Stainless Steel, J. Korea Foundry Soc. 19 (1999) 410-418.

[18] A. Bouayad, C. Gerometta, M. Radouani, A. Saka, Interface Characterization in Aluminum Alloy Casting Reinforced with SG Iron Inserts, J. Adv. Res. Mech. Eng. 1 
(2010) 226-231.

[19] W. J. Cheng, C. J. Wang, Effect of silicon on the formation of intermetallic phases in aluminide coating on mild steel, Intermet. 19 (2011) 1455-1460.

[20] M. Hartlieb, Aluminum alloys for structural die casting, Die Cast. Eng. May (2013) $40-43$.

[21] J.S. Shin, S.H. Ko, K.T. Kim, Development and characterization of low-silicon cast aluminum alloys for thermal dissipation, J. Alloys \& Compd. 644 (2015) 673-686.

[22] J.S. Shin, T.H. Kim, D.E. Kim, D.K. Kim, K.T. Kim, Castability and mechanical properties of new 7xxx aluminum alloys for automotive chassis/body applications, J. Alloys \& Compd. 698 (2017) 577-590.

[23] L. Agudo, D. Eyidi, C.H. Schmaranzer, E. Arenholz, N. Jank, J. Bruckner, A.R. Pyzalla, J. Mater. Sci. 42 (2007) 4205-4214.

[24] P. Protsenko, A. Terlain, V. Traskine, N. Eustathopoulos, Scr. Mater. 45 (2001) $1439-1445$.

[25] G.W. Dallin, The Role of Aluminum in Continuous Hot-Dip Galvanizing, GalvInfoNote-10, Rev 2.1 Aug-2003.

[26] V.N. Kiselevskii, V.V. Kovalev, V.A. Stepanenko, A.I. Stukalov, V.M. Gritsina, RESISTANCE OF A ZIRCONIUM ALLOY TO CORROSION CRACKING UNDER STRESSES, Strength of Mater. 30 (1998) 197-203.

[27] O.N. Senkov, G.B. Wilks, D.B. Miracle, C.P. Chuang, P.K. Liaw, Refractory highentropy alloys, Intermet. 18 (2010) 1758-1765.

[28] L. Shao, Y. Shi, J.K. Huang, S.J. Wu, Effect of joining parameters on microstructure of dissimilar metal joints between aluminum and galvanized steel, Mater. \& Des. 66 (2015) 453-458. 
[29] H. Springer, A. Szczepaniak, D. Raabe, On the role of zinc on the formation and growth of intermetallic phases during interdiffusion between steel and aluminium alloys, Acta Mater. 96 (2015) 203-211.

[30] M. Yan, Z. Fan, Review Durability of materials in molten aluminum alloys, J. Mater. Sci. 36 (2001) 285- 295.

[31] M.J. Kang, C.H. Kim, Joining Al 5052 alloy to aluminized steel sheet using cold metal transfer process, Mater. \& Des. 81 (2015) 95-103.

[32] K. Bouche', F. Barbier, A. Coulet, Intermetallic compound layer growth between solid iron and molten aluminium, Mater. Sci. \& Eng. A249 (1998) 167-175.

[33] R.W. Richards, R.D. Jones, P.D. Clements, H. Clarke, Metallurgy of continuous hot dip aluminizing, Int Mater. Rev. 39 (1994) 191-212.

[34] A. Bahadur, O.N. Mohanty, Structural studies of hot dip aluminized coatings on mild steel, Mater. Trans. JIM 32 (1991) 1053-1061.

[35] W. Deqing, S. Ziyuan, Z. Longjiang, A liquid aluminum corrosion resistance surface on steel substrate, Appl. Surf. Sci. 214 (2003) 304-311.

[36] H. Springer, A. Kostka, J.F. dos Santos, D. Raabe, Influence of intermetallic phases and Kirkendall-porosity on the mechanical properties of joints between steel and aluminium alloys, Mater. Sci. \& Eng. A528 (2011) 4630-4642.

[37] T.P.C. Klaver, G.K.H. Madsen, R. Drautz, A DFT study of formation energies of FeeZneAl intermetallics and solutes, Intermet. 31 (2012) 137-144.

[38] A.A. Bouavad, C. Gerometta, A. Belkebir, A. Ambari, Kinetic interactions between solid iron and molten aluminum. Mater. Sci. Eng. A363 (2003) 53-61.

[39] L. Jia, J. Shichun, S. Yan, N. Cong, J. Chen, H. Genzhe, Effects of zinc on the laser welding of an aluminum alloy and galvanized steel, J. Mater. Process. Technol. 224 
(2015) 49-59.

[40] H. Dong, L. Yang, C. Dong, S. Kou, Improving arc joining of Al to steel and Al to stainless steel, Mater. Sci. \& Eng. A534 (2012) 424- 435.

[41] FactSage FTlite Database, FactSage Version 6.1, May 2009.

[42] R. Monroe, Porosity in Castings, AFS Trans., 113 (2005), pp. 519-546. 
Table 1 Chemical composition of A356 aluminum alloy used (values shown in wt.\%)

Table 2 Chemical compositions of the DP980-GI and DP590-GA steels used (values shown in wt.\%)

Table 3 Energy-dispersive X-ray spectroscopy (EDS) analysis of compositions of the points marked (1) to (5) in Fig. 10

Table 4 Energy-dispersive X-ray spectroscopy (EDS) analysis of compositions of the points marked (1) to (9) in Fig. 12

Table 5 Energy-dispersive X-ray spectroscopy (EDS) analysis of compositions of the points marked (1) to (5) in Fig. 15

Table 6 Energy-dispersive X-ray spectroscopy (EDS) analysis of compositions of the points marked (1) to (6) in Fig. 17

Fig. 1. (a) mold with thin plate type multi flow channels used for fluidity test and (b) fluidity test casting.

Fig. 2. (a) mold used for the preparation of cast-bonded ingot to evaluate the interfacial bonding strength and (b) cast-bonded ingot. 
Fig. 3. Tensile shear specimens used to evaluate interfacial bonding strengths.

Fig. 4. Cross-sections of (a) as-galvanized (GI) and (b) galvannealed (GA) steels with increasing sandblasting time. AR, SB5 and SB30 designate the sandblasting times of 0 sec (as-received state), $5 \mathrm{sec}$, and $30 \mathrm{sec}$, respectively.

Fig. 5. Effects of zinc-coated steel type and sandblasting time on the fluidity which was the flow length of aluminum alloy melt in a thin cavity formed by the zinc-coated steel insert and the mold wall. AR, SB5 and SB30 designate the sandblasting times of 0 sec (as-received state), $5 \mathrm{sec}$ and $30 \mathrm{sec}$ respectively.

Fig. 6. Typical load-displacement curve for cast-bonded GI steel/aluminum bimetals.

Fig. 7. Effects of zinc-coated steel type and sandblasting time on the interfacial bonding strength.

Fig. 8. Shape change of A356 aluminum alloy droplets on the (a) GI and (b) GA steels with increasing sandblasting time.

Fig. 9. Variations of surface roughness average $(R a)$ of the steel inserts as functions of zinc-coated steel type and sandblasting time.

Fig. 10. Fractured surfaces of tensile shear specimens of cast-bonded AR-GA steel/aluminum bimetals: (a) steel and (b) aluminum sides. 
Fig. 11. Representative photographs showing the variation of fracture surface morphologies of the tensile shear specimens according to sandblasting: cast-bonded (a) AR-GI/aluminum and (b) SB5-GI/aluminum bimetals.

Fig. 12. Fractured surfaces of tensile shear specimens according to sandblasting: castbonded (a) AR-GI/aluminum and (b) SB5-GI/aluminum bimetals.

Fig. 13. X-ray diffraction patterns on fractured surfaces of tensile shear specimens of the cast-bonded GI steel/aluminum bimetals as a function of sandblasting time: (a) steel and (b) aluminum sides.

Fig. 14. Cross-sectional microstructures of as-cast-bonded GI steel/aluminum joints with increasing sandblasting time: (a) $0 \mathrm{sec}$, (b) $5 \mathrm{sec}$, and (c) $30 \mathrm{sec}$.

Fig. 15. Cross-sectional microstructures of as-cast-bonded GI steel/aluminum joints with increasing sandblasting time: (a) $0 \mathrm{sec}$, (b) $5 \mathrm{sec}$, and (c) $30 \mathrm{sec}$.

Fig. 16. EDS line scan results across the bonding interface of cast-bonded ARGI/aluminum specimens.

Fig. 17. Cross-sectional microstructures of the interfacial areas of the quenched ARGI/aluminum specimens obtained by quenching into water immediately after pouring 
the molten aluminum on GI steels.

Fig. 18. Schematic illustrations of $\mathrm{Zn}$ coating behavior and interfacial microstructure evolution during the solid-liquid compound casting of GI steel/A356 aluminum alloy bimetals: (a) un-sandblasted and (b) sandblasted GI steels. 
Table 1 Chemical composition of A356 aluminum alloy used in this study (values shown in wt.\%)

\begin{tabular}{|c|c|c|c|c|c|c|c|c|}
\hline Element & $\mathrm{Si}$ & $\mathrm{Mg}$ & $\mathrm{Cu}$ & $\mathrm{Ti}$ & $\mathrm{Mn}$ & $\mathrm{Zn}$ & $\mathrm{Fe}$ & $\mathrm{Al}$ \\
\hline \hline Content & 7.0 & 0.4 & 0.2 & 0.3 & 0.1 & 0.1 & 0.2 & bal. \\
\hline
\end{tabular}


Table 2 Chemical compositions of the DP980-GI and DP590-GA steels used in this study (values shown in wt.\%)

\begin{tabular}{|c|c|c|c|c|c|c|c|c|c|}
\hline Element & $\mathrm{C}$ & $\mathrm{Si}$ & $\mathrm{Mn}$ & $\mathrm{Cr}$ & $\mathrm{Mo}$ & $\mathrm{Al}$ & $\mathrm{Cu}$ & $\mathrm{Ni}$ & $\mathrm{Fe}$ \\
\hline \hline DP590-GA & 0.07 & 0.20 & 1.95 & 0.30 & 0.05 & 0.03 & 0.10 & 0.10 & bal. \\
\hline DP980-GI & 0.15 & 0.31 & 1.50 & 0.02 & 0.01 & 0.05 & 0.02 & 0.01 & bal. \\
\hline
\end{tabular}


Table 3 Energy-dispersive X-ray spectroscopy (EDS) analysis of the compositions of the points marked (1) to (5) in Fig. 10

\begin{tabular}{|c|r|r|r|r|r|r|r|r|r|c|}
\hline \multirow{2}{*}{ Point } & \multicolumn{2}{|c|}{$\mathrm{Al}$} & \multicolumn{2}{|c|}{$\mathrm{Si}$} & \multicolumn{2}{|c|}{$\mathrm{Fe}$} & \multicolumn{2}{|c|}{$\mathrm{Zn}$} & \multicolumn{2}{|c|}{ O } \\
\cline { 2 - 12 } & $\mathrm{wt} \%$ & at\% & $\mathrm{wt} \%$ & at\% & $\mathrm{wt} \%$ & at\% & $\mathrm{wt} \%$ & at\% & wt\% & at\% \\
\hline \hline$(1)$ & 30.58 & 49.27 & - & - & 10.03 & 7.81 & 57.72 & 38.39 & 1.67 & 4.53 \\
\hline$(2)$ & 91.78 & 96.44 & - & - & - & - & 8.22 & 3.56 & - & - \\
\hline$(3)$ & 44.41 & 60.71 & 1.92 & 2.53 & 32.95 & 21.76 & 18.83 & 10.62 & 1.90 & 4.38 \\
\hline$(4)$ & 60.50 & 64.07 & 32.16 & 32.72 & - & - & 7.34 & 3.21 & - & - \\
\hline$(5)$ & 47.13 & 68.36 & - & - & - & - & 52.87 & 31.64 & - & - \\
\hline
\end{tabular}


Table 4 Energy-dispersive X-ray spectroscopy (EDS) analysis of the compositions of the points marked (1) to (9) in Fig. 12

\begin{tabular}{|c|r|r|r|r|r|r|r|r|}
\hline \multirow{2}{*}{ Point } & \multicolumn{2}{|c|}{$\mathrm{Al}$} & \multicolumn{2}{|c|}{$\mathrm{Fe}$} & \multicolumn{2}{|c|}{$\mathrm{Si}$} & \multicolumn{2}{|c|}{ Zn } \\
\cline { 2 - 10 } & wt\% & at\% & wt\% & at\% & wt\% & at\% & wt $\%$ & at\% \\
\hline \hline$(1)$ & 49.50 & 62.70 & 39.95 & 24.45 & 10.55 & 12.84 & - & - \\
\hline$(2)$ & 5.85 & 11.34 & 93.60 & 87.64 & 0.55 & 1.02 & - & - \\
\hline$(3)$ & 51.05 & 62.49 & 34.31 & 20.29 & 14.64 & 17.22 & - & - \\
\hline$(4)$ & 46.19 & 62.33 & 49.79 & 32.46 & 4.02 & 5.21 & - & - \\
\hline$(5)$ & 51.11 & 64.35 & 39.05 & 23.75 & 9.84 & 11.90 & - & - \\
\hline$(6)$ & - & - & 100.00 & 100.00 & - & - & - & - \\
\hline$(7)$ & 96.49 & 96.62 & - & - & 3.51 & 3.38 & - & - \\
\hline$(8)$ & 96.68 & 97.50 & 0.69 & 0.33 & 1.93 & 1.87 & 0.70 & 0.29 \\
\hline$(9)$ & 42.98 & 57.16 & 46.21 & 29.69 & 9.90 & 12.65 & 0.91 & 0.50 \\
\hline
\end{tabular}


Table 5 Energy-dispersive X-ray spectroscopy (EDS) analysis of the compositions of the points marked (1) to (5) in Fig. 15

\begin{tabular}{|c|r|r|r|r|r|r|r|c|c|}
\hline \multirow{2}{*}{ Point } & \multicolumn{2}{|c|}{$\mathrm{Al}$} & \multicolumn{2}{|c|}{$\mathrm{Si}$} & \multicolumn{2}{|c|}{$\mathrm{Fe}$} & \multicolumn{2}{|c|}{$\mathrm{Zn}$} & \multirow{2}{*}{ Inference phase } \\
\cline { 2 - 9 } & $\mathrm{wt} \%$ & at\% & wt\% & wt\% & at\% & at $\%$ & wt\% & at\% & \\
\hline \hline$(1)$ & 55.94 & 67.21 & 31.50 & 31.50 & 18.29 & 18.29 & - & - & $\mathrm{Al}_{8} \mathrm{Fe}_{2} \mathrm{Si}$ \\
\hline$(2)$ & 56.21 & 65.54 & 26.20 & 26.20 & 14.76 & 14.76 & - & - & $\mathrm{Al}_{4.5} \mathrm{FeSi}$ \\
\hline$(3)$ & 57.56 & 72.35 & 3.40 & 4.10 & 37.14 & 22.56 & 1.90 & 0.99 & $\mathrm{Al}_{13} \mathrm{Fe}_{4}$ \\
\hline$(4)$ & 58.01 & 69.80 & 31.92 & 31.92 & 18.56 & 18.56 & - & - & $\mathrm{Al}_{8} \mathrm{Fe}_{2} \mathrm{Si}_{1}$ \\
\hline$(5)$ & 57.49 & 66.80 & 25.69 & 25.69 & 14.42 & 14.42 & - & - & $\mathrm{Al}_{4.5} \mathrm{FeSi}$ \\
\hline
\end{tabular}


Table 6 Energy-dispersive X-ray spectroscopy (EDS) analysis of the compositions of the points marked (1) to (6) in Fig. 17

\begin{tabular}{|c|r|r|r|r|r|c|}
\hline \multirow{2}{*}{ Point } & \multicolumn{2}{|c|}{ Zn } & \multicolumn{2}{c|}{$\mathrm{Al}$} & \multicolumn{2}{c|}{ Si } \\
\cline { 2 - 7 } & wt\% & at\% & wt\% & at\% & wt\% & at\% \\
\hline \hline$(1)$ & 100.00 & 100.00 & - & - & - & - \\
\hline$(2)$ & 95.49 & 89.72 & 4.51 & 10.28 & - & - \\
\hline$(3)$ & 90.26 & 79.28 & 9.74 & 20.72 & - & - \\
\hline$(4)$ & 23.65 & 11.33 & 76.35 & 88.67 & - & - \\
\hline$(5)$ & - & - & 2.76 & 2.87 & 97.24 & 97.13 \\
\hline$(6)$ & 23.99 & 11.59 & 64.71 & 75.71 & 11.30 & 12.70 \\
\hline
\end{tabular}



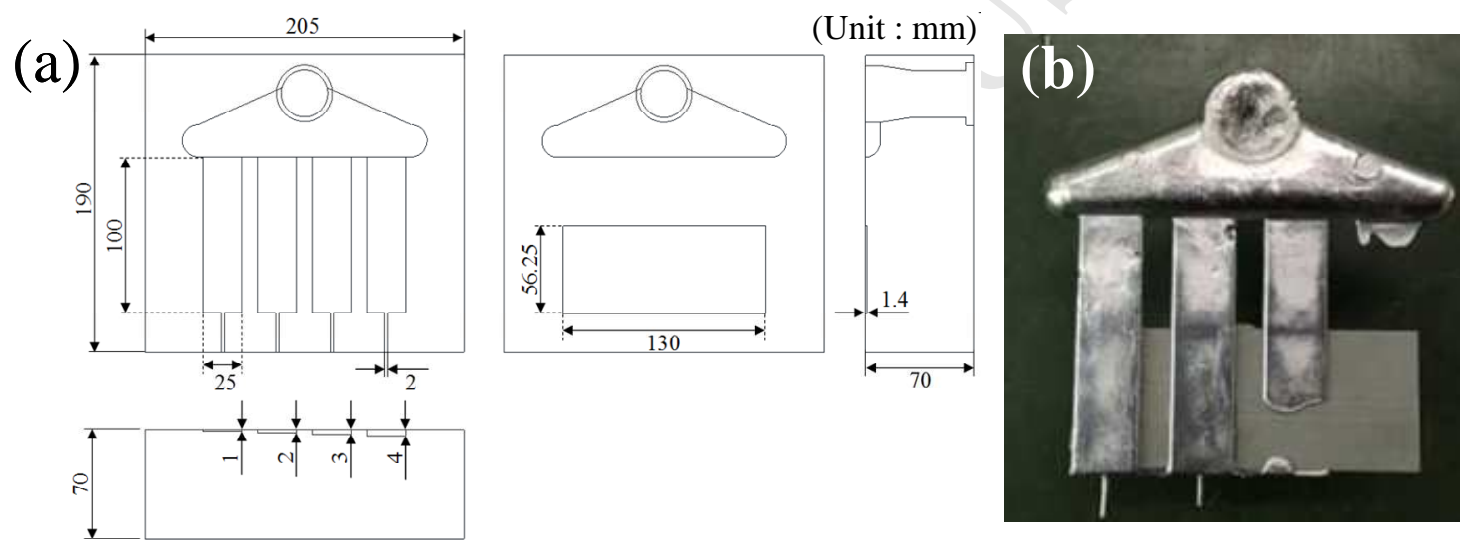

Fig. 1. 

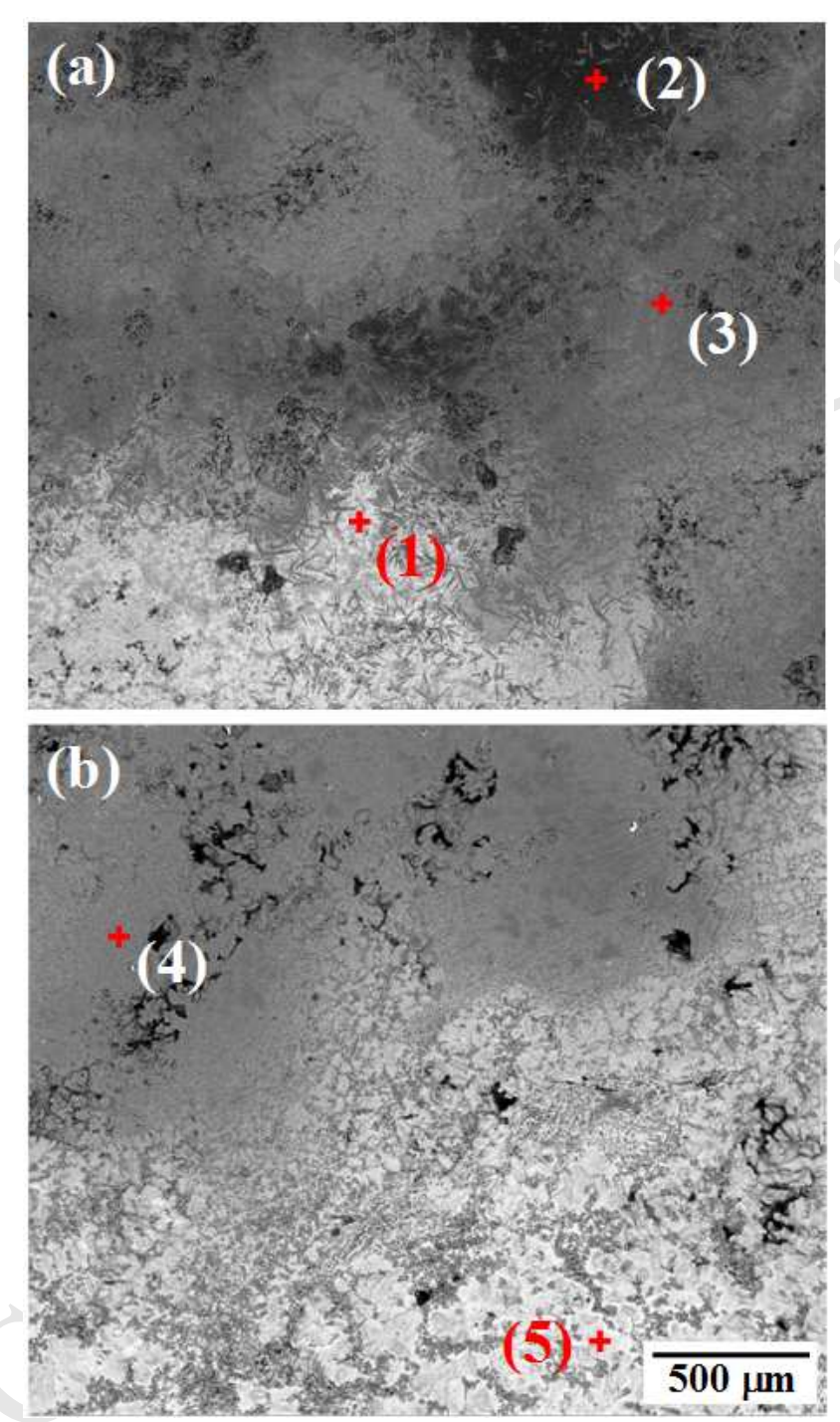

Fig. 10. 


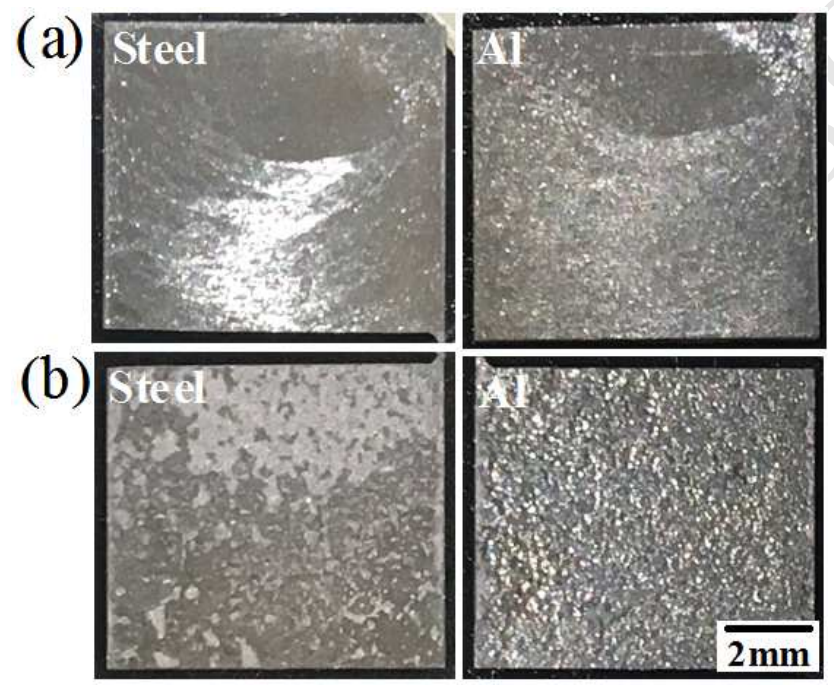

Fig. 11. 
(a) Steel

(b)
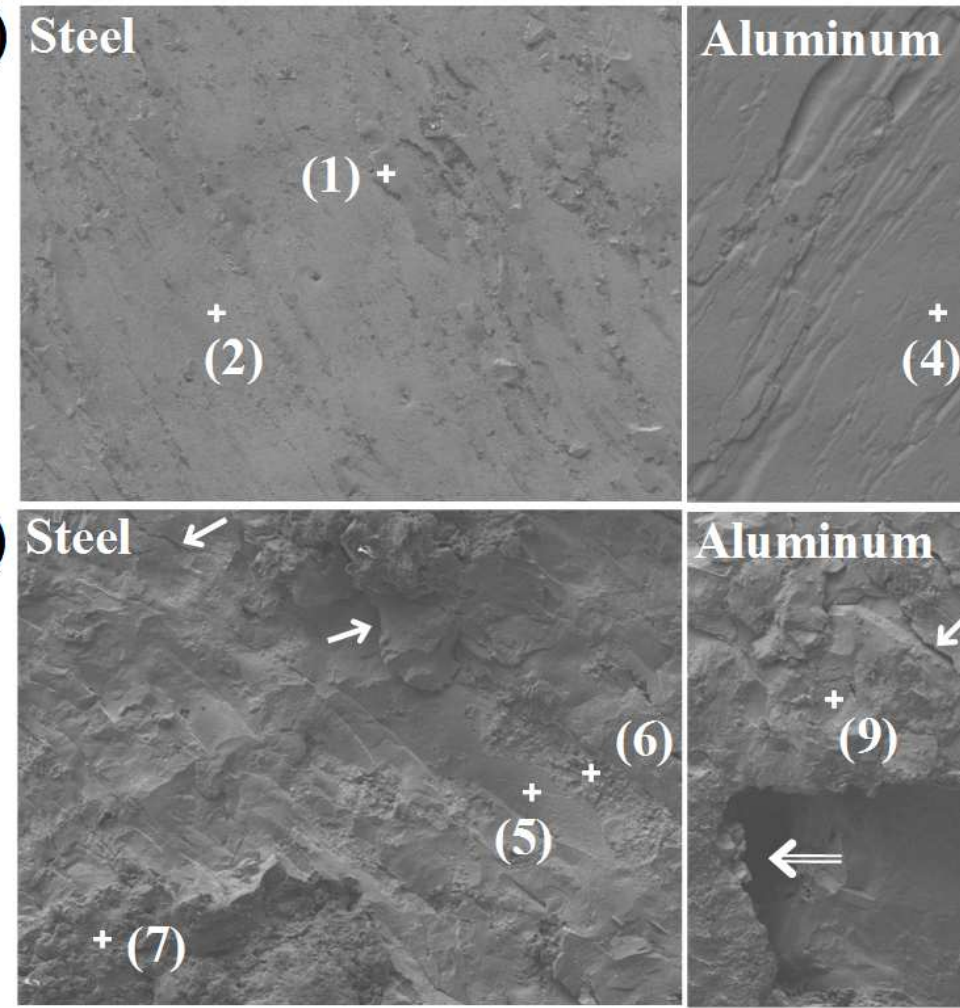

$+(3)$

(2)

(4)

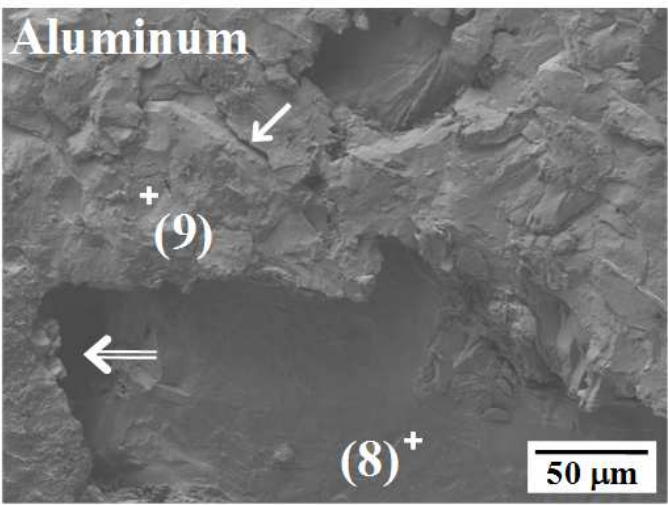

Fig. 12. 


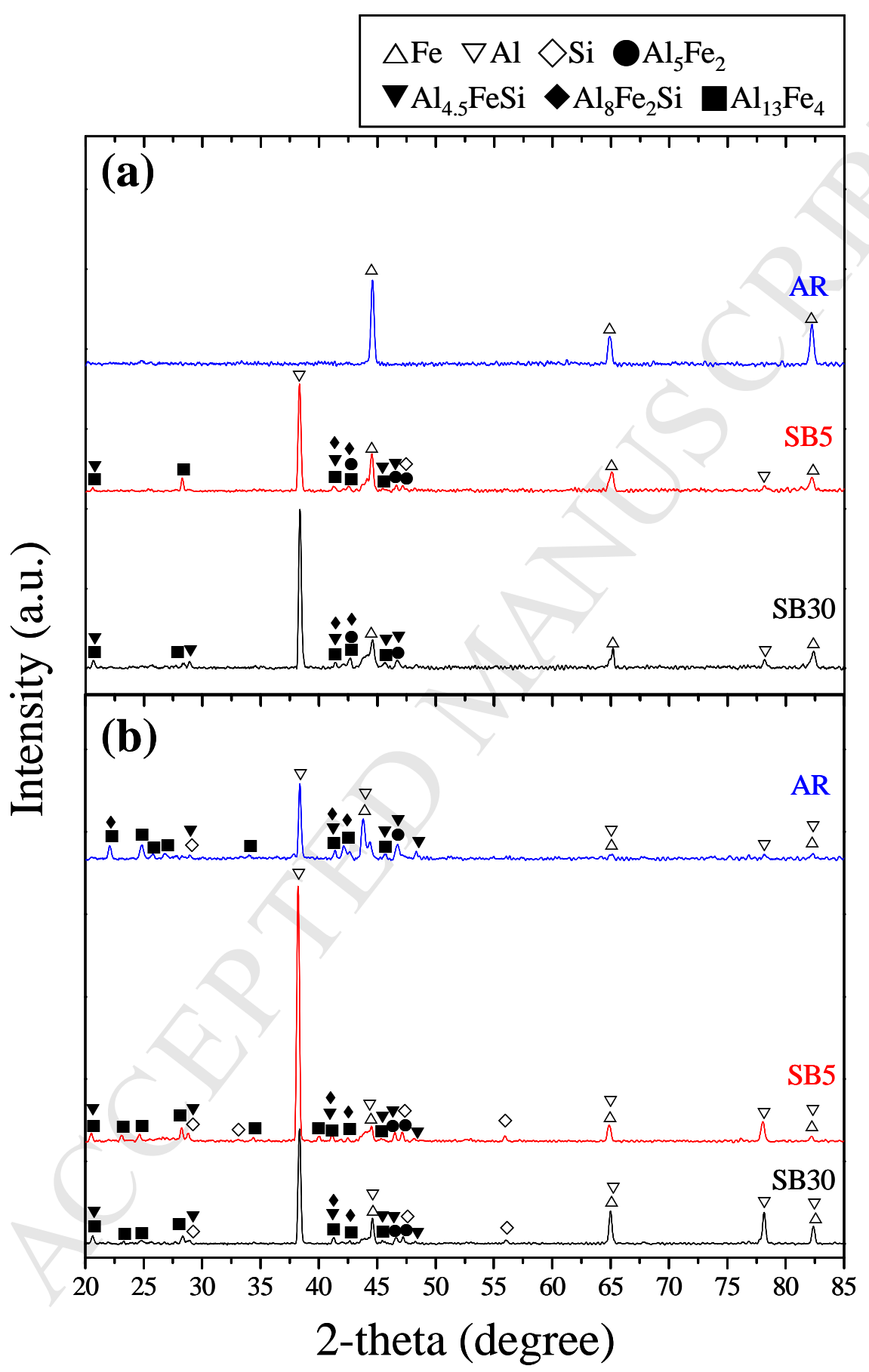

Fig. 13. 

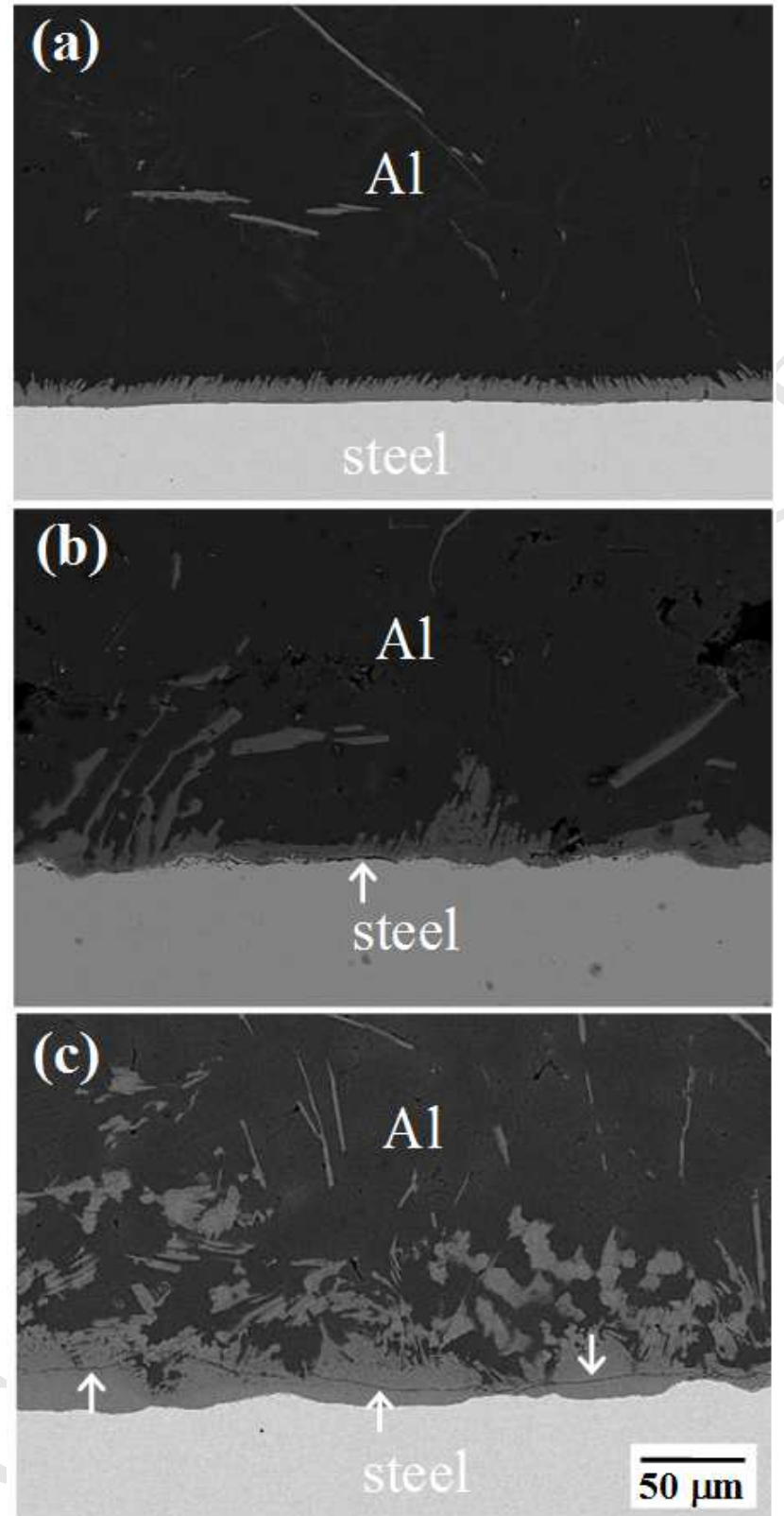

Fig. 14. 

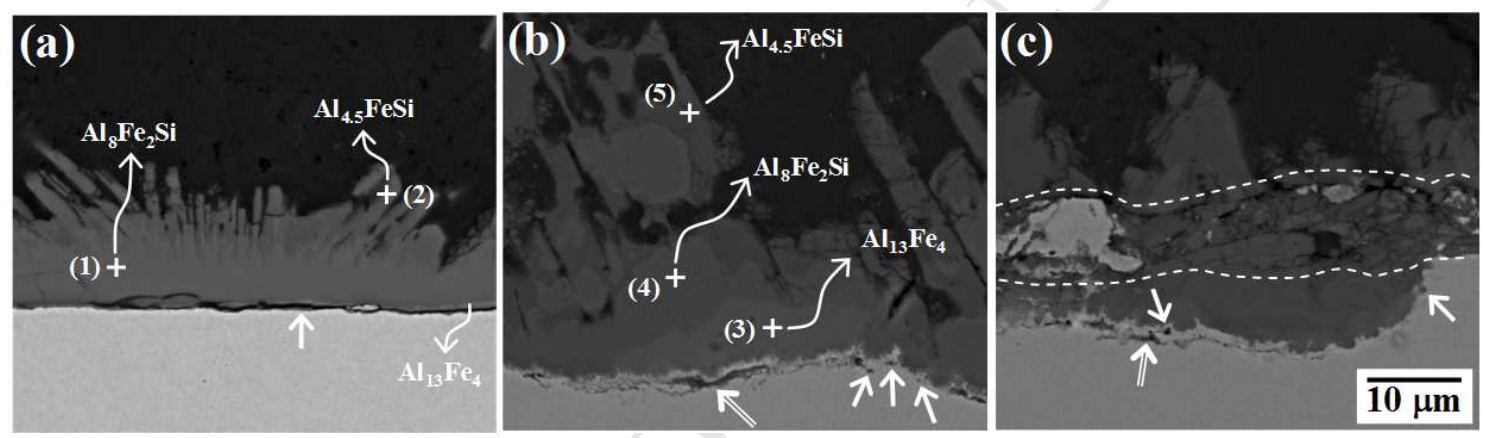

Fig. 15. 


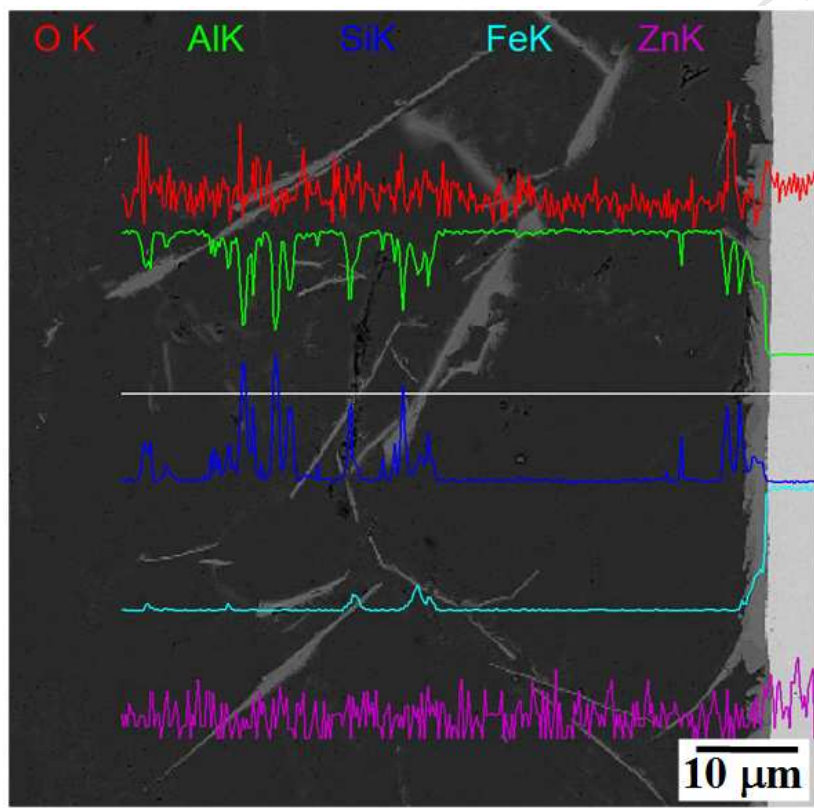

Fig. 16. 

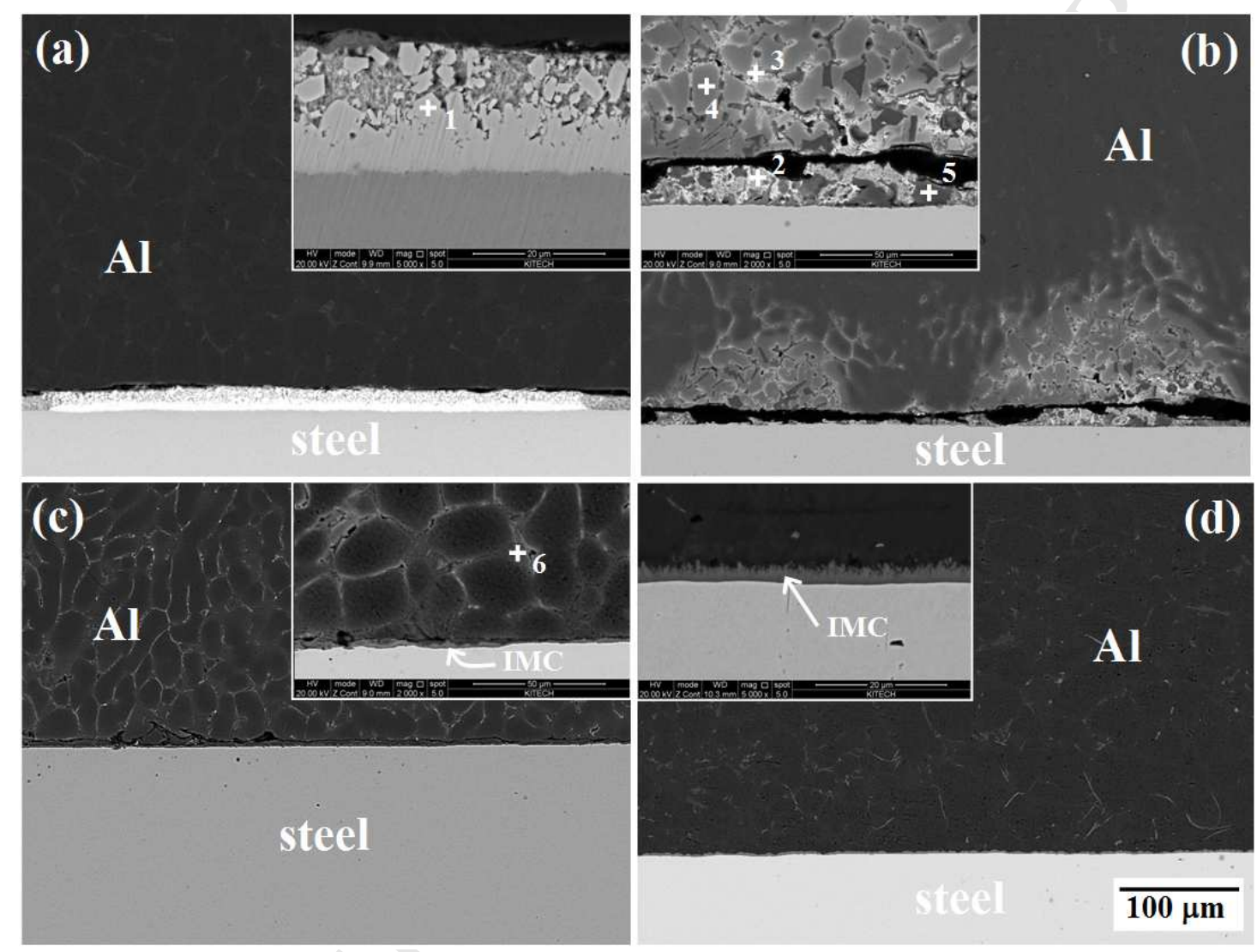

Fig. 17. 

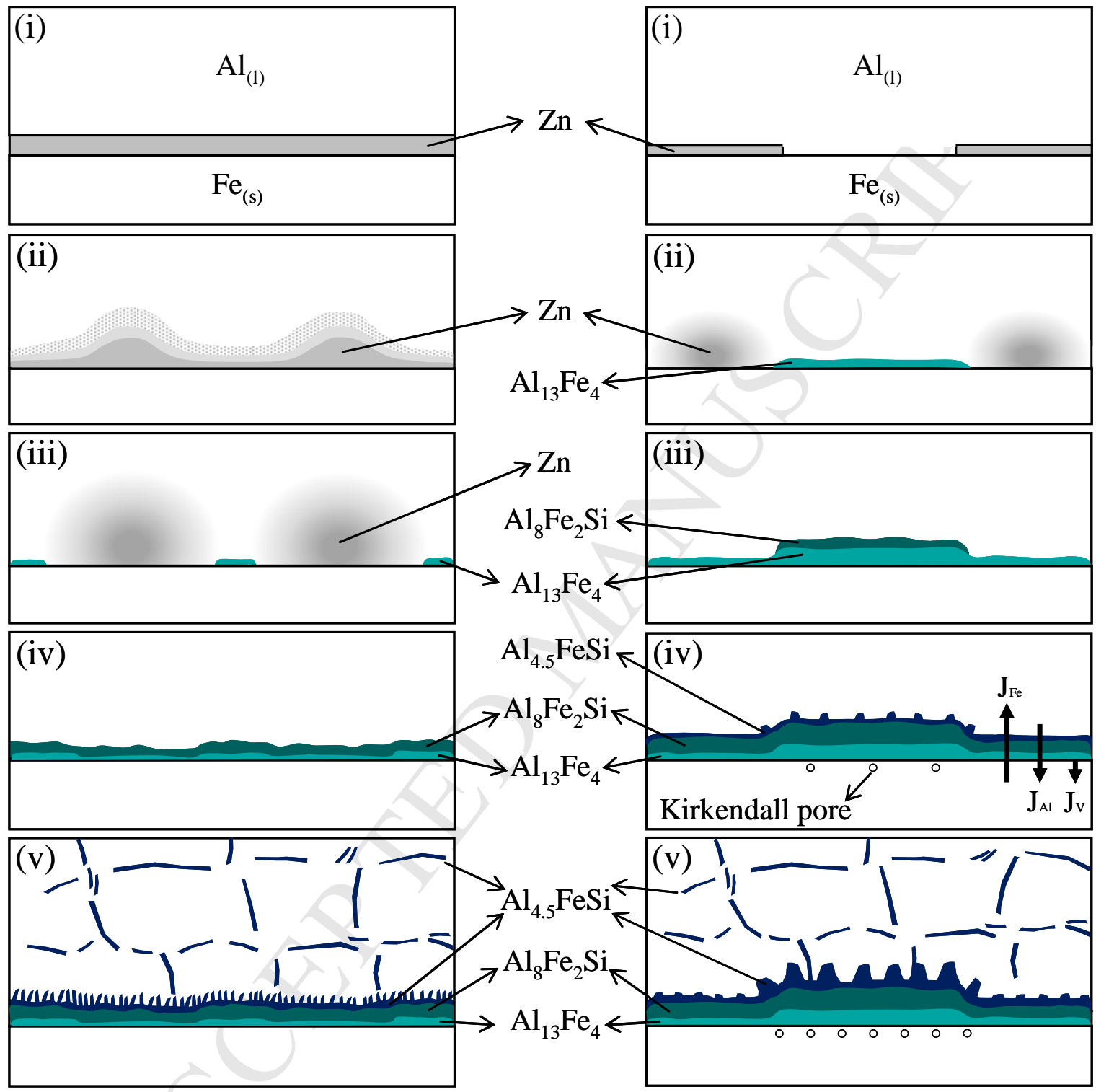

(a)

(b)

Fig. 18. 
(a)
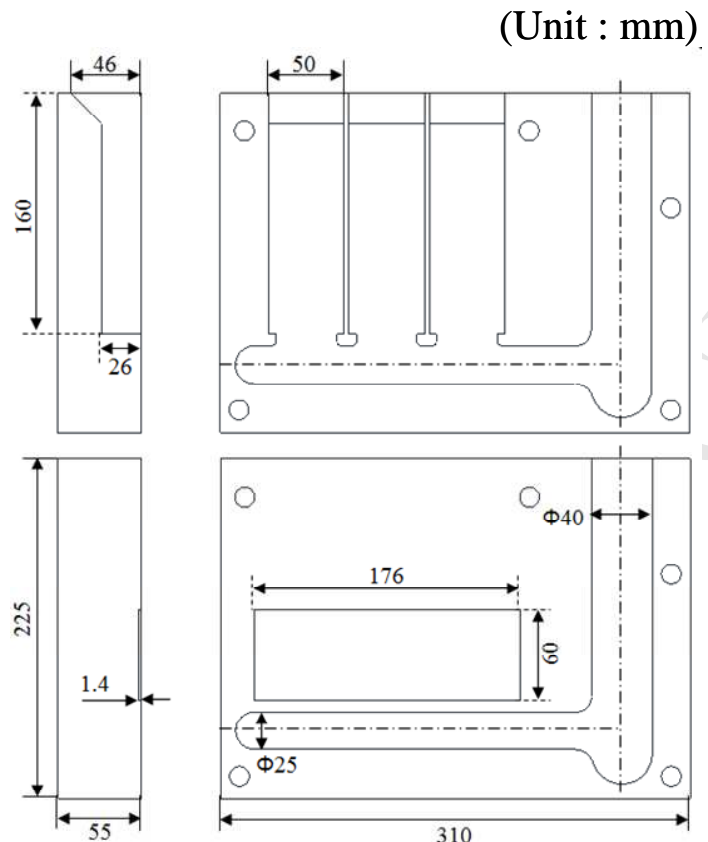

(b)

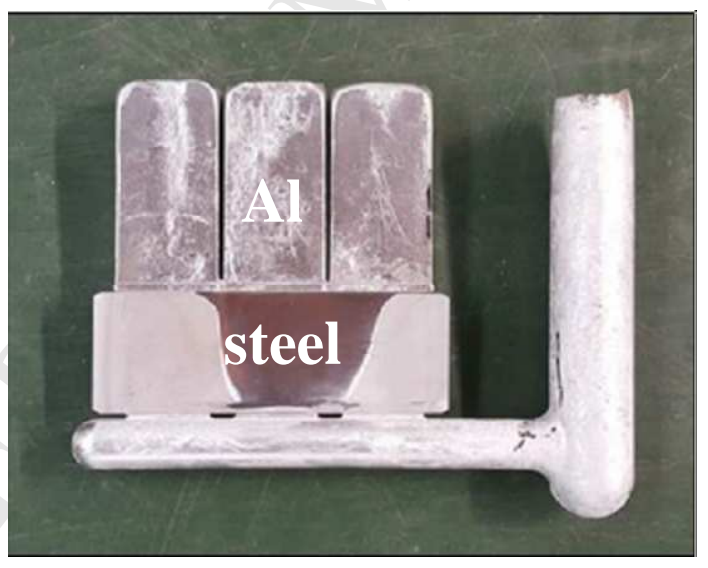

Fig. 2. 


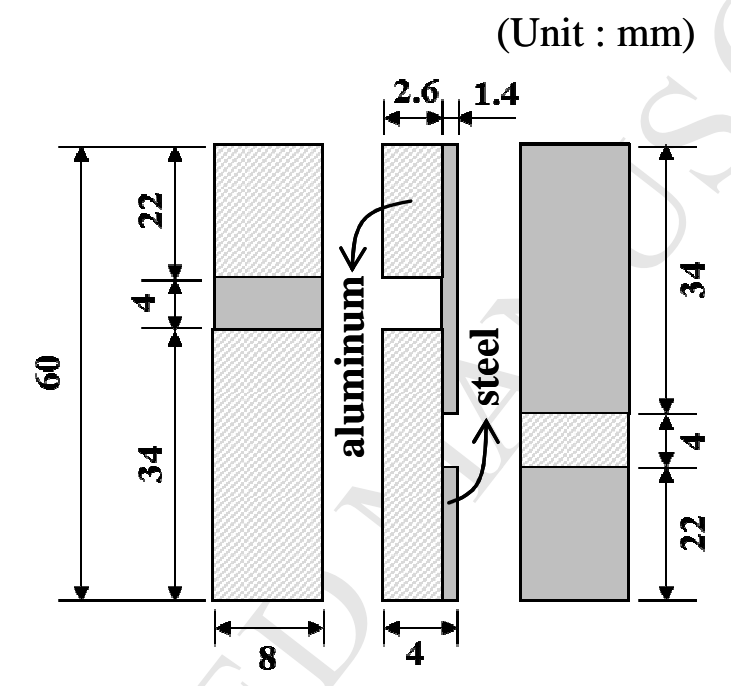

Fig. 3. 


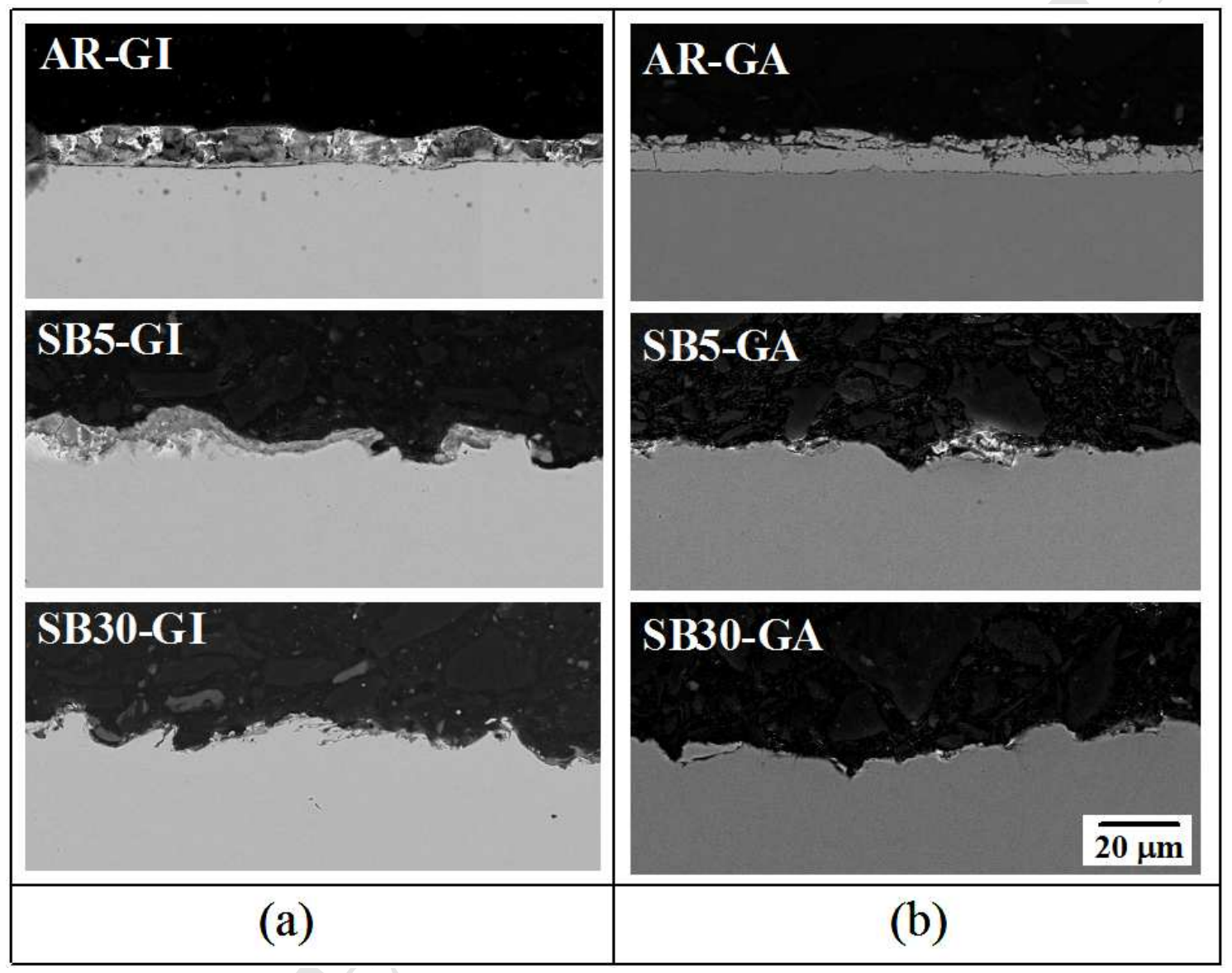

Fig. 4. 


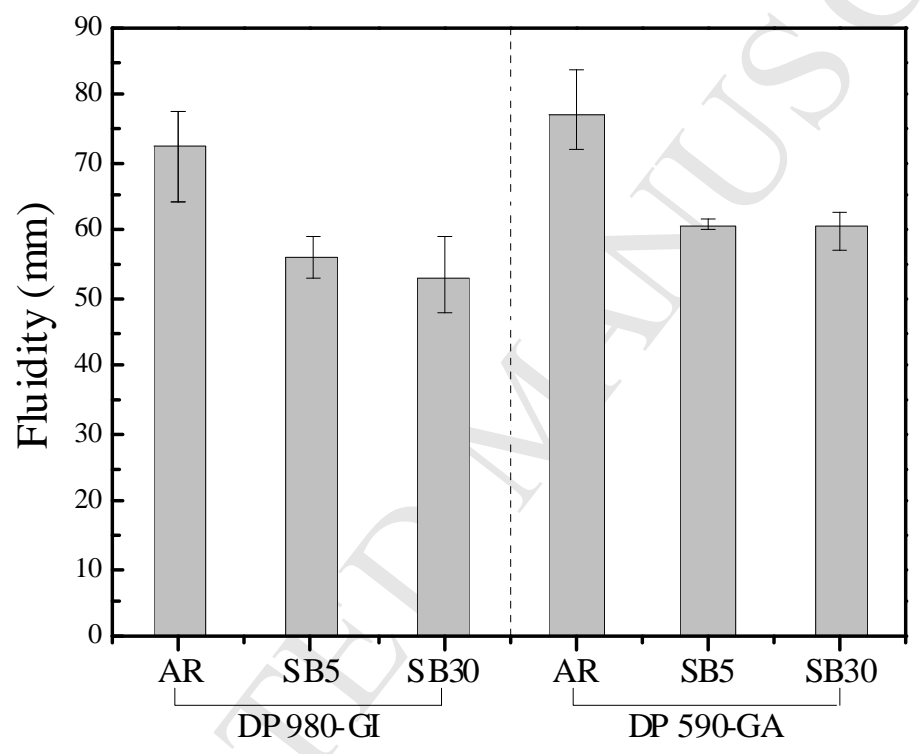

Fig. 5. 


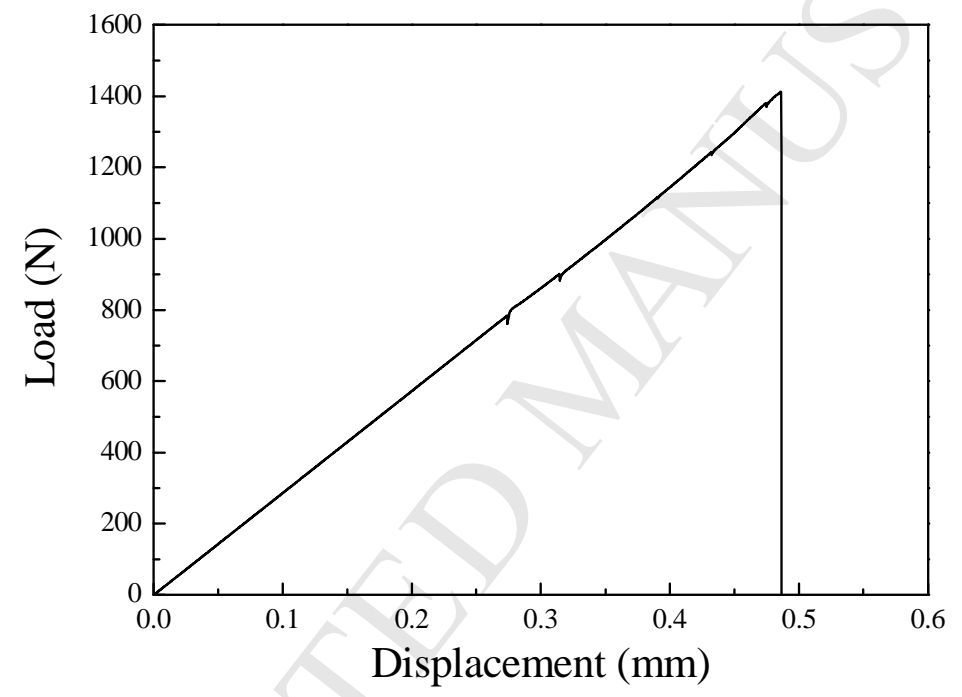

Fig. 6. 


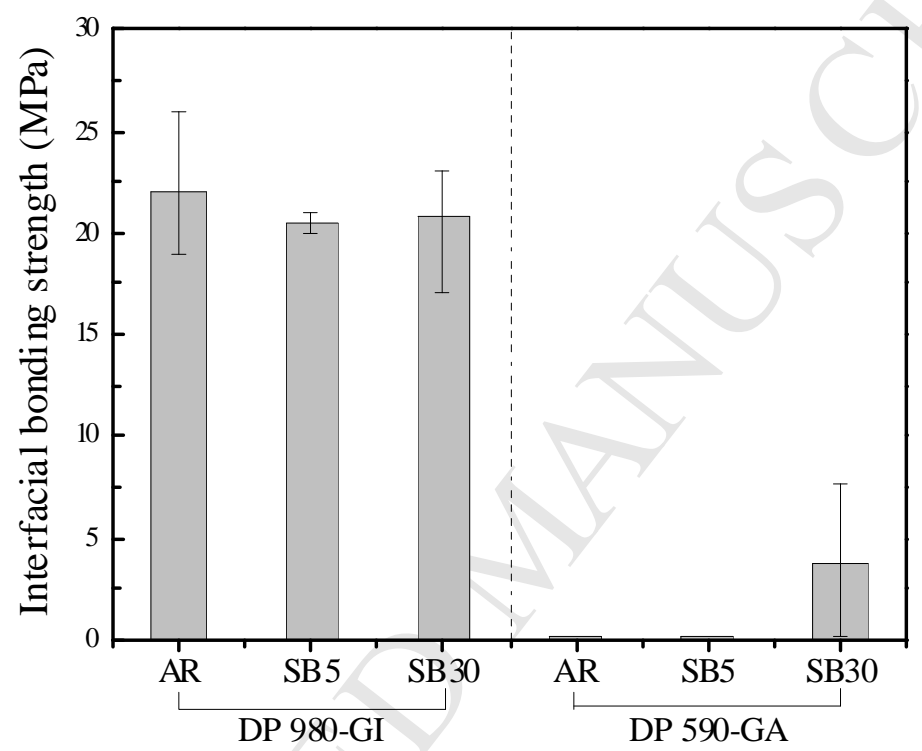

Fig. 7. 
(a)

(b)

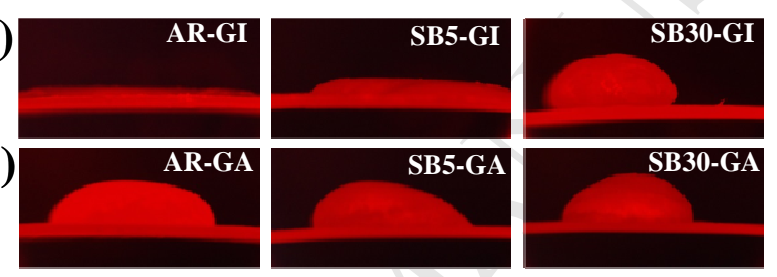

Fig. 8. 


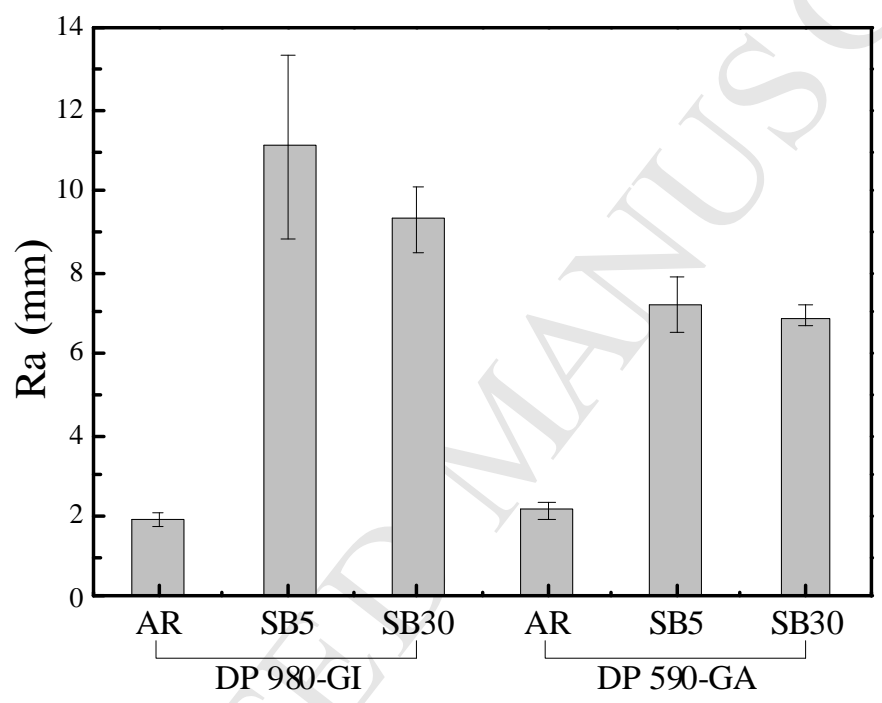

Fig. 9. 
The solid-liquid compound casting of layered aluminum/zinc-coated steel is studied. Effects of zinc-coated steel type and sandblasting pretreatment are investigated.

Low temperature short time bonding and high Si content determine interfacial phases. Sandblasting spurs intermetallic phase growth, changing the main fracture sites. The behavior of $\mathrm{Zn}$ coating and its effect on bonding reaction control are proposed. 